\title{
Le colostrum, un lait particulièrement riche en de nombreux composants : peut-on en déceler la présence dans les livraisons de lait de vache?
}

\author{
Didier Levieux* \\ Unité d'immunochimie, station de recherches sur la viande, \\ Inra, Theix, 63122 Saint-Genès-Champanelle, France
}

(Reçu le 28 octobre 1998 ; accepté le 7 mai 1999)

\begin{abstract}
Colostrum, a milk particularly rich in numerous components. Is it possible to detect its unlawful addition in milk supplies? The concentration of numerous proteins, enzymes, hormones, growth factors, vitamins, mineral and trace elements decreases abruptly during the first milkings post-partum and then increases in late lactation and during the udder involution before calving. Therefore, colostrum cannot be precisely defined since it is a milk all the more abnormal than it is milked closer from calving. So its unlawful addition to milk supply may only be detected by the modification of the normal composition of the milk. From all the components reviewed, IgG are the most documented and sensitive indicators of an abnormal milk. They can be easily quantified using a semi-automatised single radial immunodiffusion technique and threshold values characteristic of an abnormal milk have been defined taking into account the volume of the milk supply. (C) Inra/ Elsevier, Paris.
\end{abstract}

colostrum / milk quality / IgG / automatised radial immunodiffusion

Résumé - De nombreuses protéines, enzymes, hormones, facteurs de croissance, vitamines, minéraux et oligoéléments voient leur concentration baisser brutalement au cours des premières traites qui suivent la mise-bas, puis augmenter en fin de lactation et pendant l'involution de la mamelle qui précède la mise-bas. Le colostrum ne peut donc être défini avec précision puisqu'il s'agit d'un lait dont la composition est d'autant plus anormale que l'on se rapproche de la mise-bas. Son addition dans les livraisons de lait ne peut donc être décelée que par la mise en évidence d'une modification de la composition normale du lait. Parmi tous les composants examinés, les IgG sont actuellement les marqueurs les plus documentés et les plus sensibles du caractère anormal du lait consécutif à la présence de colostrum, de laits de mammites ou de fin de gestation. Leur dosage par immunodiffusion radiale semi-automatisée est particulièrement simple et des valeurs seuils permettant de conclure au caractère anormal d'un lait en fonction du litrage ont été établies. (C) Inra/Elsevier, Paris.

colostrum / qualité du lait / IgG / immunodiffusion radiale semi-automatisée

* Correspondance et tirés à part. levieux@clermont.inra.fr 


\section{INTRODUCTION}

«Le lait est le produit intégral de la traite totale et ininterrompue d'une femelle laitière bien portante, bien nourrie et non surmenée. Il doit être recueilli proprement et ne pas contenir de colostrum ».

Cette définition du lait destiné à la consommation humaine, fixée en 1909 par le Congrès international de la répression des fraudes, a été complétée en France par le décret du 25 mars 1924 qui précise dans son article 2 :

«Ne peut être considéré comme lait propre à la consommation humaine : 3 . Le lait provenant d'une traite opérée moins de $7 \mathrm{j}$ après le part, et d'une manière générale, le lait contenant du colostrum ».

Si les critères qui ont présidé historiquement à l'instauration de ce délai de $7 \mathrm{j}$ ont été essentiellement des critères microbiologiques, les progrès réalisés sur le plan sanitaire - notamment en ce qui concerne l'éradication de la tuberculose et de la brucellose - sont tels qu' aujourd'hui on peut légitimement se poser la question du bien-fondé d'un tel délai. Certains pays n'imposent que $3 \mathrm{j}$ (Suisse, Hongrie, Tchécoslovaquie, ÉtatsUnis) ou $4 \mathrm{j}$ (Allemagne). Au Canada, la législation diffère selon les provinces : le Manitoba interdit la livraison du lait des 7 premiers jours mais d'autres provinces ne l'interdisent que pendant 3 à $5 \mathrm{j}$ [156]. En France on constate en fait que peu d'éleveurs respectent la législation : selon Quesnel [109] $74 \%$ d'entre-eux livrent le lait dans les $5 \mathrm{j}$ qui suivent le vélage.

La définition d'un lait « contenant du colostrum » est problématique, compte-tenu de la difficulté qu'il y a déjà à définir le colostrum. Rochaix et Tapernoux notaient en 1942 [123] : « Tout ce que l'on peut dire c'est que le colostrum précède le lait et sa composition après le part tend vers celle du lait qui est finalement sécrété, entre le troisième et le quatorzième jour après le part ».

Même en acceptant de définir le colostrum de façon très restrictive comme le lait de la première traite, le problème n'est pas résolu puisque le passage du colostrum au lait s'effectue de façon progressive : au troisième jour de lactation le lait contient encore 5 à $10 \%$ de colostrum et 1 à $2 \%$ au septième jour. Le législateur n'a pas précisé à partir de quel pourcentage on peut considérer qu'un lait ne contient plus de colostrum.

La Fédération internationale de laiterie, dans son dictionnaire de terminologie de 1983 définit (en anglais) le lait comme :

«Le produit de la sécrétion mammaire normale, obtenu par une ou plusieurs traites, sans aucune addition ni soustraction ».

Cette définition est à la fois plus globale et plus ouverte. Il suffit de définir ce qu'est un lait « normal » sur des critères bactériologiques, cellulaires ou physico-chimiques et de définir, sur les mêmes critères, en quoi le colostrum est un lait « anormal ». Il est alors possible de calculer la quantité de colostrum admissible, c'est-à-dire celle qui ne rend pas le lait « anormal ».

Le colostrum, outre sa richesse en cellules (essentiellement polynucléaires), se caractérise essentiellement par une concentration très élevée en protéines et, plus particulièrement, en protéines solubles (tableau I). Cette situation est liée au système de transmis-

Tableau I. Composition du colostrum et du lait, exprimée en $\mathrm{g} \cdot \mathrm{L}^{-1}$ (d'après Mahieu [83]).

Tableau I, Composition of colostrum and milk expressed as $\mathrm{g} \cdot \mathrm{L}^{-1}$ (adapted from Mahieu, [83]).

\begin{tabular}{lrc}
\hline & $\begin{array}{c}\text { Première } \\
\text { traite }\end{array}$ & $\begin{array}{c}\text { Après } \\
10 \mathrm{j} .\end{array}$ \\
\hline Densité & 1,06 & 1,032 \\
\hline Matières grasses & 50 & 39 \\
Matières azotées & 160 & 35 \\
$\quad$ - caséines & 30 & 27 \\
- albumines & 40 & 4,5 \\
- globulines & 80 & 0,7 \\
Lactose & 30 & 4,9 \\
Sels minéraux & 12 & 8 \\
\hline
\end{tabular}


sion de l'immunité : le jeune ruminant, contrairement à l'enfant, naît agamma-globulinémique ; son taux d'immunoglobulines $\mathrm{G}$ (IgG) sériques est généralement inférieur à $0,1 \mathrm{mg} \cdot \mathrm{mL}^{-1}$. Dépourvu de défenses immunitaires humorales contre les agressions bactériennes et virales qu'il rencontre dès la naissance, il doit sa survie à la grande richesse du colostrum maternel en IgG (40 à $100 \mathrm{mg} \cdot \mathrm{mL}^{-1}$ selon les races) et à sa faculté d'absorber intactes ces IgG pendant les 24 premières heures de vie, ce qui lui permet d'acquérir en quelques heures les défenses immunitaires de sa mère.

Le colostrum contient également un grand nombre d'autres substances - l'inventaire est loin d'en être terminé - à concentrations beaucoup plus élevées que dans le lait et qui en font une véritable «potion magique » pour le veau : vitamines, oligoéléments, hormones, facteurs de croissance, enzymes, inhibiteurs d'enzymes et autres substances dont les fonctions ne sont pas toutes élucidées.

Cette composition particulière du colostrum a des conséquences technologiques importantes pour l'industriel : « gratinage » des pasteurisateurs du fait de la sensibilité des IgG aux traitements thermiques, baisse des rendements fromagers malgré un surpaiement du lait, mauvais égouttage des caillés favorisant le développement de moisissures, augmentation de la lipolyse enzymatique, inhibition ou augmentation de la protéolyse selon les systèmes enzymatiques concernés, etc.

La concentration de ces substances chute de façon exponentielle dès les premières traites post-partum. Elle suit la diminution progressive de la capacité de l'intestin du veau à absorber intactes les macromolécules telles que les IgG, absorption qui devient quasiment nulle après les premières $24 \mathrm{~h}$ de vie. La sécrétion lactée n'est donc plus qu'un « demi-colostrum » à la deuxième traite et qu'un « quart de colostrum » à la troisième traite. Dès le $3^{\mathrm{e}} \mathrm{j}$ post-partum il reste moins de $10 \%$ de colostrum dans les sécrétions lactées. Après le $5^{\mathrm{e}} \mathrm{j}$ de lactation, le taux d'IgG du lait n'est plus statistiquement différent, au seuil de $1 \%$, de celui du lait du $8^{\mathrm{e}} \mathrm{j}$ dont la livraison commence à être autorisée [75], ce qui pose la question du bienfondé de l'attente des « $7 \mathrm{j}$ après le part ».

L'objectif de cette synthèse bibliographique est de faire le point des connaissances sur la nature des composants qui différencient le colostrum du lait et lui confèrent son caractère de lait « anormal ». L'analyse de l'évolution de ces composants dans d'autres laits « anormaux » tels que les laits de mammites ou de fin de lactation nous a ensuite conduit à choisir parmi ces composants celui dont la mesure paraît la mieux adaptée à la mise en évidence de la présence de colostrum dans du lait, ou tout au moins à définir le caractère « anormal » d'un lait.

\section{LES COMPOSANTS MAJEURS DU COLOSTRUM}

Le colostrum de première traite se distingue principalement du lait par son extrême richesse en immunoglobulines ; aucun autre liquide biologique n'en contient des concentrations aussi élevées. Parmi les immunoglobulines, ce sont les IgG qui prédominent, et tout particulièrement la sousclasse $I_{g G}$ qui représente $90 \%$ des IgG. La richesse du colostrum en cette sous-classe résulte d'un phénomène de concentration sélective à partir du pool des IgG sériques [10, 25, 67].

Les concentrations moyennes d' $\mathrm{IgG}_{1}$ colostrales rapportées dans la littérature sont extrêmement variables [72], allant de $18 \mathrm{mg} \cdot \mathrm{mL}^{-1}$ [58] à $92 \mathrm{mg} \cdot \mathrm{mL}^{-1}$ [89]. Si le faible nombre d'animaux analysés explique une bonne partie de ces écarts, l'effet race et des aspects méthodologiques concernant les techniques de dosage en expliquent une autre partie. On peut considérer actuellement que les vaches laitières Frisonnes-Holstein et Jersiaises ont des taux moyens d'IgG 
dans le colostrum voisins de $60 \mathrm{mg} \cdot \mathrm{mL}^{-1}$ $[14,75,110]$ pour $50 \mathrm{mg} \cdot \mathrm{mL}^{-1} \mathrm{chez}$ les vaches Holstein $[39,94,108]$. Les races à viande ont des concentrations d'IgG plus élevées, de l'ordre de $100 \mathrm{mg} \cdot \mathrm{mL}^{-1}[72]$.

Les taux d' $\mathrm{IgG}_{1}$ chutent rapidement au cours des traites qui suivent le part : ils diminuent de moitié à chaque nouvelle traite pendant les deux premiers jours de lactation (figure 1) et atteignent $1 \mathrm{mg} \cdot \mathrm{mL}^{-1}$ vers le $7 \mathrm{e}$. Toutefois, le taux de base d'environ $0,5 \mathrm{mg} \cdot \mathrm{mL}^{-1}[18,71,74,96] \mathrm{n}$ 'est atteint qu'au bout de 2 à 3 mois [74]. Le rapport entre les taux d' $\mathrm{IgG}_{1}$ du colostrum et du lait des vaches laitières est donc particulièrement élevé, de l'ordre de 120 . Certains auteurs ont publié des concentrations d' $\mathrm{IgG}_{1}$ dans le lait allant de $0,25-0,28 \mathrm{mg} \cdot \mathrm{mL}^{-1}[78]$ à $1 \mathrm{mg} \cdot \mathrm{mL}^{-1}[138]$. Ces valeurs extrêmes sont généralement la conséquence de méthodes de dosage et d'étalonnage inappropriées (cf. $\$ 6.1$ ) [77].

Les $\mathrm{IgG}_{2}$ atteignent dans le colostrum de première traite des concentrations moyennes de $2 \mathrm{mg} \cdot \mathrm{mL}^{-1}[15,73]$ avec des valeurs extrêmes publiées comprises entre $1,6 \mathrm{mg} \cdot \mathrm{mL}^{-1}[16]$ et $6,4 \mathrm{mg} \cdot \mathrm{mL}^{-1}$ [105]. Dans le lait, la moyenne des valeurs publiées est de $0,05 \mathrm{mg} \cdot \mathrm{mL}^{-1}[73,115]$, soit un rapport colostrum/lait de 40 .

La moyenne des taux d'IgM colostrales relevés dans la littérature est de $8,7 \mathrm{mg} \cdot \mathrm{mL}^{-1}$ [15] ou $5 \mathrm{mg} \cdot \mathrm{mL}^{-1}$ [73], selon les références prises en compte. Chez les vaches Jersiaises, des travaux plus récents indiquent un taux moyen d'IgM de $2,4 \mathrm{mg} \cdot \mathrm{mL}^{-1}[110]$ à $3,4 \mathrm{mg} \cdot \mathrm{mL}^{-1}$ [111]. Dans le lait, les valeurs publiées sont plus concordantes, avec une moyenne de $0,04-0,05 \mathrm{mg} \cdot \mathrm{mL}^{-1}[73,115]$. Le rapport colostrum/lait est donc de l'ordre de 50 à 200.

Les concentrations d'IgAs colostrales sont de $3,5 \mathrm{mg} \cdot \mathrm{mL}^{-1}[15]$ à $4,0 \mathrm{mg} \cdot \mathrm{mL}^{-1}$ $[73,145]$. Dans deux études plus récentes menées sur des vaches Jersiaises, des moyennes de 1,7 et $4,5 \mathrm{mg} \cdot \mathrm{mL}^{-1}$ ont été trouvées [110, 111]. Dans le lait, les valeurs sont de l'ordre de 0,10 à $0,13 \mathrm{mg} \cdot \mathrm{mL}^{-1}$, soit

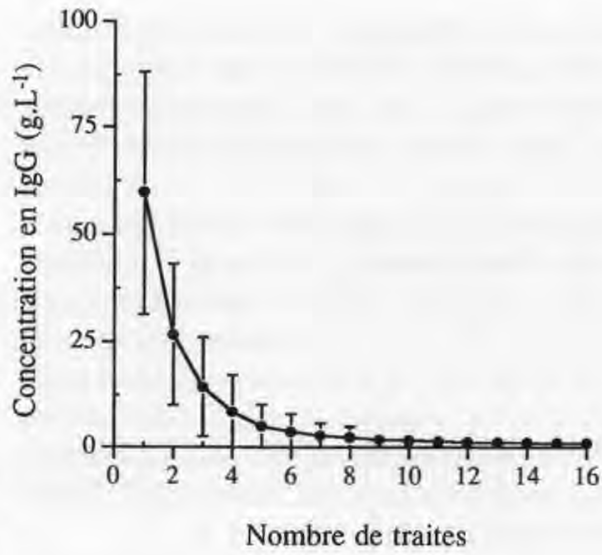

Figure 1. Évolution de la concentration moyenne des $\mathrm{IgG}_{1}\left(\mathrm{mg} \cdot \mathrm{mL}^{-1}\right)$ dans les 16 premières traites post-partum de 60 vaches Frisonnes-Holstein (d'après Levieux et Ollier [75]).

Figure 1. Changes in the concentration of $\mathrm{IgG}_{1}$ in the milk of 60 Holstein-Friesian cows during early lactation (adapted from Levieux and Ollier [75]).

un rapport colostrum/lait de l'ordre de 27 à 40 .

Les concentrations moyennes de $\beta$-lactoglobuline et d' $\alpha$-lactalbumine dans le colostrum (14 et $2 \mathrm{mg} \cdot \mathrm{mL}^{-1}$, respectivement) sont plus élevées que dans le lait $(4,5$ et $1,4 \mathrm{mg} \cdot \mathrm{mL}^{-1}$ respectivement) [75, 104]. Le rapport colostrum/lait pour ces protéines est donc faible : 3 pour la $\beta$-lactoglobuline et 1,4 pour l' $\alpha$-lactalbumine.

La concentration de lactoferrine dans le colostrum de l'ordre de $0,8 \mathrm{mg} \cdot \mathrm{mL}^{-1}$, taux qui se stabilise autour de $0,09 \mathrm{mg} \cdot \mathrm{mL}^{-1}$ au cours de la troisième semaine de lactation [126]. Des taux plus élevés $(1,25$ à $4 \mathrm{mg} \cdot \mathrm{mL}^{-1}$ ) ont été observés dans le colostrum des vaches laitières $[1,63,129]$. Les taux seraient par contre plus faibles $\left(0,5 \mathrm{mg} \cdot \mathrm{mL}^{-1}\right)$ chez les vaches à viande [1]. Il a été noté par certains auteurs que la moitié des animaux de races à viande ont des taux de lactoferrine proches de zéro [144]. Les taux chutent ensuite rapidement vers une valeur de base de $0,25-0,30 \mathrm{mg} \cdot \mathrm{mL}^{-1}$ 


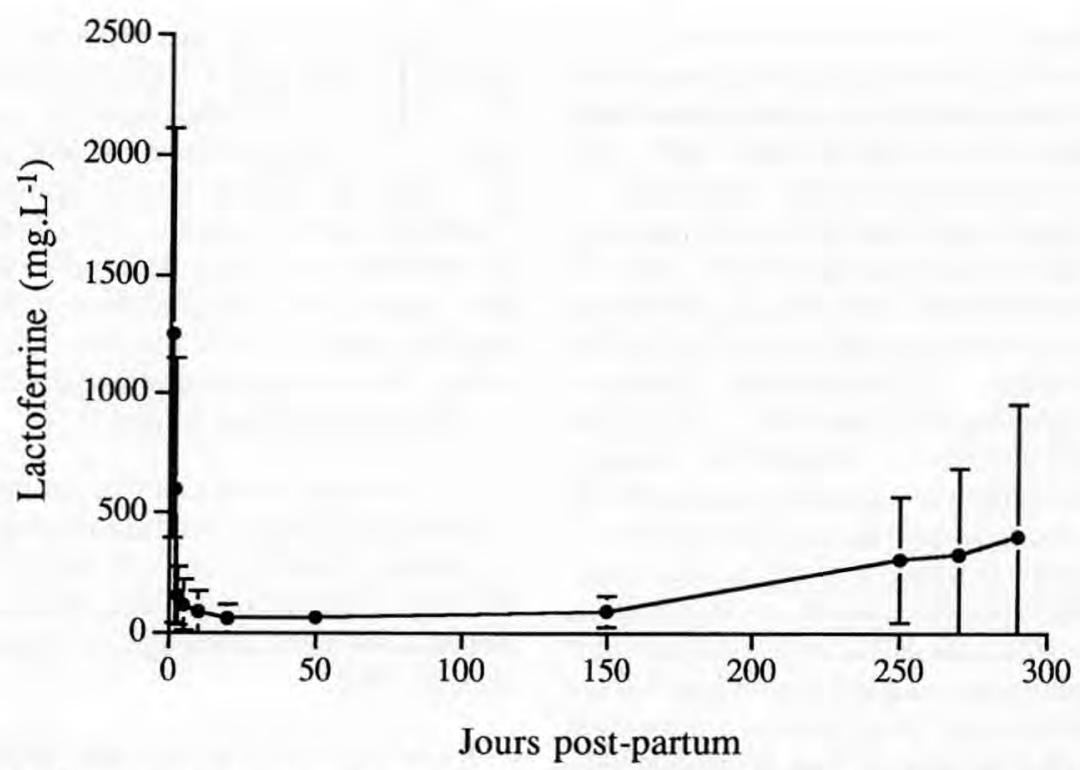

Figure 2. Évolution des concentrations moyennes de la lactoferrine au cours de la lactation (d'après les données de Senft et Klobasa [129]).

Figure 2. Changes in the concentration of lactoferrin during lactation (adapted from Senft and Klobasa [129]).

à $15-30 \mathrm{j}$ post-partum $[1,113,151]$ ou de $0,06 \mathrm{mg} \cdot \mathrm{mL}^{-1}[129]$ (figure 2). Les taux de lactoferrine augmentent ensuite progressivement au cours de la lactation pour atteindre $0,06 \mathrm{mg} \cdot \mathrm{mL}^{-1}$ et $0,15 \mathrm{mg} \cdot \mathrm{mL}^{-1}$ après respectivement 150 et $270 \mathrm{j}$ de lactation [113]. Le rapport colostrum/lait pour la lactoferrine peut donc varier entre 10 et 100 selon les auteurs et le stade de lactation des vaches.

Les concentrations colostrales de sérumalbumine sont de l'ordre de $1,2 \mathrm{mg} \cdot \mathrm{mL}^{-1}$ [75] à $2,6 \mathrm{mg} \cdot \mathrm{mL}^{-1}$ [103]. Elles chutent ensuite rapidement pour atteindre à $8 \mathrm{j}$ postpartum des valeurs de 0,14 à $0,2 \mathrm{mg} \cdot \mathrm{mg}^{-1}$ respectivement, soit un rapport colostrum/lait de 8,6 à 13 .

La concentration en transferrine du colostrum bovin est de $0,9 \mathrm{mg} \cdot \mathrm{mL}^{-1}$ [144] à $1,07 \mathrm{mg} \cdot \mathrm{mL}^{-1}$ [126]. Elle chute rapidement durant les premiers jours de lactation puis plus doucement, pour atteindre un niveau de base de $0,02 \mathrm{mg} \cdot \mathrm{mL}^{-1}$ au cours de la troisième semaine post-partum [126]. À $30 \mathrm{j}$ post-partum, le taux de transferrine du lait est de $0,025 \mathrm{mg} \cdot \mathrm{mL}^{-1}$ [113]. Le rapport colostrum/lait est donc de l'ordre de 50. Le rapport transferrine/albumine est beaucoup plus élevé dans le colostrum que dans le lait mature ou dans les laits de mammites, ce qui suggère un transport sélectif de cette protéine du sang vers le lait [126].

Un groupe de glycoprotéines acides du sérum sanguin ou du lactosérum est retenu sur DEAE cellulose à $\mathrm{pH} 4,5$. Parmi ces protéines on trouve l' $\alpha_{1}$-glycoprotéine acide, également appelée orosomucoïde, qui fait partie du groupe des protéines de la phase aiguë de l'inflammation car sa concentration sérique augmente lors de maladies inflammatoires ou de tumeurs malignes. Sa concentration est élevée dans le colostrum : $1,0 \mathrm{mg} \cdot \mathrm{mL}^{-1}$ [7] à $1,65 \mathrm{mg} \cdot \mathrm{mL}^{-1}$ [92]. Dans le lait, une concentration de $0,3 \mathrm{mg} \cdot \mathrm{mL}^{-1} \mathrm{a}$ 
été notée [7], en contradiction avec des observations plus récentes qui indiquent une diminution rapide de la concentration dans les premières $48 \mathrm{~h}$ pour atteindre $20 \%$ de la valeur initiale [92]. Au $3^{\mathrm{e}} \mathrm{j}$ de lactation la concentration serait de $0,09 \pm 0,01 \mathrm{mg} \cdot \mathrm{mL}^{-1}$ [92] soit $6 \%$ de la première traite. Dans les traites suivantes les taux d' $\alpha_{1}$-glycoprotéine acide sont inférieurs à la limite de détection $\left(0,02 \mathrm{mg} \cdot \mathrm{mL}^{-1}\right)$ de la technique d'immunoélectrophorèse en " roquettes » utilisée par Mesa et al. [92]. Il faut toutefois signaler que les conditions de purification à $\mathrm{pH} 3,0$ dénaturent la protéine et conduisent à l'obtention d'antisérums qui ne reconnaissent pas la protéine native. Les échantillons de colostrum ou de lait doivent donc subir une précipitation à $\mathrm{pH} 3,0$ pour leur dosage immunologique, précipitation qui entraîne une perte d'environ $30 \%$ de la protéine [92].

\section{LES COMPOSANTS MINEURS DU COLOSTRUM}

Nous avons classé dans ce groupe les composants à concentration inférieure au $\mathrm{mg} \cdot \mathrm{mL}^{-1}$. Il s'agit essentiellement de protéines diverses, d'enzymes, d'inhibiteurs d'enzymes, d'hormones, de facteurs de croissance, de vitamines et d'oligo-éléments.

\subsection{Protéines diverses}

En utilisant une technique immunologique très résolutive, l'immunoélectrophorèse bidimensionnelle (crossed immunoelectrophoresis), 32 composants ont été mis en évidence dans le lactosérum de vache [81]. En dehors des composants majeurs déjà cités tels que les IgG, la $\beta$-lactoglobuline, l' $\alpha$-lactalbumine ou la sérum-albumine, on trouve différentes protéines dérivées du sang comme la préalbumine, le composant C3 du complément, et l'haptoglobine. Le complément [134] et l'haptoglobine (Levieux, résultats non publiés) sont présents dans le colostrum à des concentrations plus élevées que dans le lait, sans toutefois atteindre, pour l'haptoglobine, des rapports colostrum/lait supérieurs à 10. Le complément a une activité bactéricide contre les colibacilles [12] et participe donc à la lutte contre les agressions microbiennes en compagnie d'autres protéines comme le lysozyme, la lactoferrine, le système lactopéroxydasethiocyanate-péroxyde d'hydrogène, la xanthine-oxydase ou la properdine, qui sont toutes à des concentrations plus élevées dans le colostrum que dans le lait [117].

Le colostrum bovin contient des facteurs capables de réguler la synthèse des IgE chez des espèces hétérologues, offrant ainsi une alternative thérapeutique pour la suppression des réactions allergiques médiées par les IgE [149].

Le colostrum bovin contient également divers facteurs cytotoxiques capables de réduire l'activité phagocytaire des leucocytes polynucléaires et des macrophages du lait ou du sang [142], un inhibiteur de la production d'interleukine 2 par les lymphocytes $T$ 《 helper » humains activés [125] et des activateurs du pouvoir bactéricide des lymphocytes bovins stimulés par l'interleukine 2 [130].

Une $\beta 2$-microglobuline colostrale de 11,8 kDa, a été purifiée et séquencée [47]. Elle présente $74 \%$ d'homologie avec la $\beta 2$-microglobuline humaine. Cette protéine était connue antérieurement sous le nom de « lactolline », avec des concentrations dans le colostrum et le lait de 6 et $2 \mu \mathrm{g} \cdot \mathrm{mL}^{-1}$ respectivement [34].

Le colostrum contient également d'autres protéines mineures ou des peptides qui, malgré leur présence en faibles concentrations, ont des activités biologiques importantes sur la physiologie du nouveau né en cours d'allaitement. Il en est ainsi de la bradikinine et des kininogènes [117, 155], d'un facteur de mobilisation des lipides qui augmente les taux d'acides gras circulants chez le veau nouveau né [33] ou de facteurs de croissance qui seront décrits plus loin $(\$ 3.5)$. 


\subsection{Enzymes}

Plus de 60 enzymes ont été répertoriées dans le lait, parmi lesquelles une bonne vingtaine ont été identifiées comme endogènes dont l' $\alpha$-L-fucosidase, la glucose-6-phosphate isomérase, la phosphodiestérase, l' $\alpha$-mannosidase [157] ou la galactosyltransferase [93].

La lactopéroxydase est l'enzyme quantitativement la plus importante du lait $\left(0,03 \mathrm{mg} \cdot \mathrm{mL}^{-1}\right)$. Sa concentration augmente après le part pour atteindre un maximum au $4^{\mathrm{e}} \mathrm{j}$ puis diminuer les jours suivants. Dans le lait de femme le phénomène est inverse, avec une très forte concentration dans le colostrum qui chute ensuite rapidement jusqu'à des taux très faibles dans le lait [118].

L'activité de la phosphatase alcaline chute de 267 à $41 \mu \mathrm{mol} \cdot \mathrm{min}^{-1} \cdot \mathrm{kg}^{-1}$ entre la première et la huitième traite [80]. La N-acetyl- $\beta$-glucosaminidase est présente dans le colostrum à des taux 20 fois plus élevés que dans le lait $[49,56]$ et son activité chute rapidement dans les jours qui suivent le part (figure 3).

Des concentrations de $401 \mathrm{ng} \cdot \mathrm{mL}^{-1} \mathrm{de}$ lysozyme dans le colostrum, pour $96 \mathrm{ng} \cdot \mathrm{mL}^{-1}$ au $3^{\mathrm{e}} \mathrm{j}$ de lactation, ont été mises en évidence [35].

La gamma-glutamyl transferase, enzyme essentiellement liée aux membranes, est présente dans le colostrum à des taux de l'ordre de $19000 \mathrm{U} \cdot \mathrm{L}^{-1}$ [145] soit 2,5 à 3,3 fois plus élevés que dans le lait et environ 300 fois plus élevés que dans le sérum. Le dosage de cette enzyme ne permet donc pas de différencier facilement le colostrum du lait mais a été proposé comme test d'absorption du colostrum par le veau [13, 143].

La plasmine est la protéinase majeure du lait. Toutefois, comme de nombreuses autres enzymes et inhibiteurs d'enzymes, elle provient du sérum, sous la forme de son précurseur inactif, le plasminogène. Le mode de transport du plasminogène à partir du sang n'est pas encore élucidé mais on sait que sa

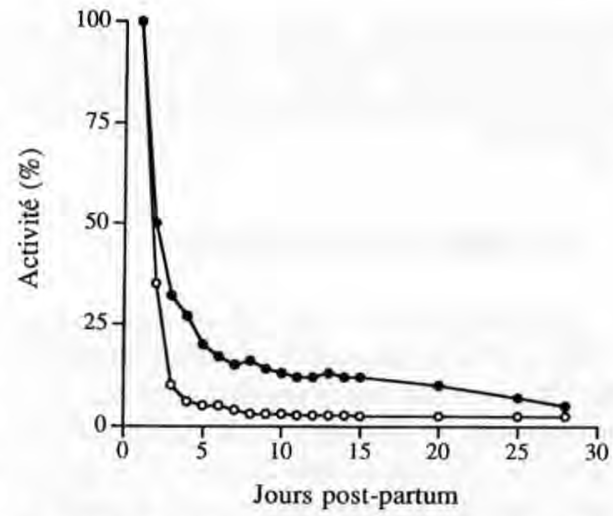

Figure 3. Évolution de l'activité de la N-acétyl$\beta$-glucosaminidase $(-$ ) et de l'inhibiteur de la trypsine $(O)$ au cours du premier mois de lactation (d'après Kaartinen et Pyorala [56]).

Figure 3. Changes in the activity of $\mathrm{N}$-acetyl$\beta$-glucosaminidase $(-$ and trypsin inhibitor $(O)$ during the first month of lactation (adapted from Kaartinen and Pyorala [56]).

transformation en plasmine requiert la présence d'activateurs présents dans le sang et plusieurs tissus [107]. À l'aide d'une technique Elisa utilisant des anticorps monoclonaux [26], les taux moyens de plasmine dans le colostrum et le lait ont été établis respectivement à 0,49 et $0,04 \mu \mathrm{g} \cdot \mathrm{mL}^{-1}$, soit un rapport colostrum/lait de l'ordre de 12 [27].

La procathepsine D et la cathepsine D ont été mises en évidence dans le colostrum et le lait de vache, mais les concentrations relatives n'ont pas été déterminées. Ces enzymes ont la capacité de dégrader les caséines $\alpha s_{1}, \alpha s_{2}, \beta$ et $\kappa$ ainsi que l' $\alpha$-lactalbumine, mais pas la $\beta$-lactoglobuline [66].

Le colostrum présente des activités estérasiques élevées pouvant provenir du sang ou des cellules somatiques, ainsi que de fortes activés tributyrasique et lipasique [21]. La lipase colostrale est cependant différente de la lipoprotéine-lipase, car non stimulée par le sérum sanguin et stable à $\mathrm{pH} 4,6$; de plus, l'activité lipoprotéine-lipase est très réduite dans le colostrum. Ceci pourrait 
expliquer le faible taux de lipolyse spontanée du colostrum malgré sa richesse en composés sanguins et en cellules somatiques $[21,124]$.

\subsection{Inhibiteurs d'enzymes}

Le colostrum contient en moyenne $0,39 \mathrm{mg} \cdot \mathrm{mL}^{-1} \mathrm{~d}^{\prime} \alpha_{2}$-macroglobuline, protéine sérique de haut poids moléculaire qui est, notamment, un inhibiteur de la trypsine [103]. Après le part, la concentration en $\alpha_{2}$-macroglobuline chute rapidement pour atteindre une valeur de base à $0,0045 \mathrm{mg} \cdot \mathrm{mL}^{-1}$ au cours de la deuxième semaine de lactation, soit un rapport colostrum/lait de 87 .

Le colostrum est riche en $\alpha_{1}$-antitrypsine $[68,105,127]$ qui pourrait jouer un rôle protecteur contre le clivage protéolytique des IgG. Chez les vaches Jersiaises, les concentrations en $\alpha_{1}$-antitrypsine sont comprises entre 0,25 et $0,8 \mathrm{mg} \cdot \mathrm{mL}^{-1}$ et sont légèrement corrélées $(r=0,57)$ avec les taux d'IgG [111]. Deux formes distinctes ont été identifiées: l'une, de $13 \mathrm{kDa}$, serait présente uniquement dans le colostrum et l'autre, de $70 \mathrm{kDa}$, serait également présente dans les laits de mammite où elle protègerait les tissus mammaires et les protéines du lait contre la protéolyse par les protéases leucocytaires [45]. Les concentrations en inhibiteur de la trypsine sont environ 40 fois plus élevées dans le colostrum que dans le lait, la chute étant très importante pendant les 3 premiers jours de lactation (figure 3) [56].

Un inhibiteur des sérines-protéases a été isolé. Sa masse moléculaire est comparable à celle de l' $\alpha_{1}$-antitrypsine $(60 \mathrm{kDa})$ mais son point isoélectrique est plus élevé [150]. Un inhibiteur des cystéine-protéinases de faible masse moléculaire $(12,8 \mathrm{kDa})$ et très basique $(\mathrm{pI}=10,0)$ a été purifié à partir du colostrum bovin puis séquencé [43].

Des inhibiteurs de la plasmine, l' $\alpha_{2}$-antiplasmine et le plasminogen activator inhibitor-1, ont été récemment identifiés. Ces deux inhibiteurs sont présents sous plusieurs formes, probablement par la formation de complexes avec d'autres protéines du lait. Les formes prédominantes ont des masses moléculaires de $60 \mathrm{kDa}$ pour l' $\alpha_{2}$-anti-plasmine et $55 \mathrm{kDa}$ pour le plasminogen activator inhibitor-1 [107]. Les concentrations relatives de tous ces inhibiteurs dans le colostrum et le lait ne sont pas encore établies.

\subsection{Hormones}

Le colostrum est riche en insuline, avec des taux de 0,67 à $5,7 \mathrm{nmol} \cdot \mathrm{L}^{-1}(4,02$ à $\left.34,4 \mathrm{ng} \cdot \mathrm{mL}^{-1}\right)$, soit 100 fois supérieurs à ceux du sang $[15,145]$. Le rapport de l'activité insulinique du colostrum et du lait de vaches Holstein serait de 37 [147].

Les concentrations en cortisol total et cortisol libre dans le colostrum sont respectivement de 4,4 et $1,8 \mathrm{ng} \cdot \mathrm{mL}^{-1}$. Dans le lait ces valeurs sont de 0,35 et $0,30 \mathrm{ng} \cdot \mathrm{mL}^{-1}$ [128] soit des rapports colostrum/lait de 12,6 et 6 respectivement.

Le colostrum contient des concentrations de prolactine $\left(152 \mathrm{ng} \cdot \mathrm{mL}^{-1}\right)$ et de progestérone $\left(2,6 \mathrm{ng} \cdot \mathrm{mL}^{-1}\right)$ trois fois plus élevées que dans le lait [57]. Les taux d'œstrogènes totaux, d'œstrone, d'œstradiol $17 \alpha$ et $17 \beta$ sont voisins des taux plasmatiques mais environ deux fois plus élevés que dans le lait [57].

Une angiogénine de 14,6 kDa a été isolée et séquencée. Elle présente $65 \%$ d'homologie avec l'angiogénine humaine et $32 \%$ d'homologie avec la RNase pancréatique bovine [82]. Ses concentrations relatives dans le colostrum et le lait ne sont pas connues.

\subsection{Facteurs de croissance}

L'existence de facteurs de croissance dans le colostrum des ruminants a été rapportée dès le début des années 1980 sans que les substances responsables aient toujours été complètement identifiées $[60,61$, $141,155]$. Certains de ces facteurs ont per- 
mis d'obtenir 35 à $40 \%$ de l'activité du sérum de veau fœetal pour la multiplication cellulaire d'hybridomes, avec une production équivalente d' $\mathrm{IgG}$ par cellule [100, 102]. D'autres, tel le milk growth factor (MGF), exercent une activité immunosuppressive sur les lymphocytes T humains stimulés par un antigène, des mitogènes ou des interleukines [139].

L'activité de stimulation de la croissance cellulaire est présente dans le lait humain tout au long de la lactation mais n'est présente dans le lait de vache que pendant la phase colostrale [131]. Le lait de vache obtenu $60 \mathrm{~h}$ post-partum ne conserverait que $1 \%$ de l'activité présente dans le colostrum [136].

Dans le lait humain, trois types de facteurs de croissance ont été identifiés. L'un d'eux, le HMGF III (human milk growth factor $I I I)$, représente $75 \%$ de l'activité totale. Il a une masse moléculaire de $6 \mathrm{kDa}$ et un pI entre 4,4 et 4,7 , caractéristiques très proches de celles de 1'EGF (epidermal growth factor). Dans le colostrum bovin, on ne retrouve pas ce pseudo-EGF mais un constituant de 30 à $35 \mathrm{kDa}$ inactivable par le traitement au dithiothreitol, qui est comparable à un composant minoritaire $(20 \%$ de l'activité) du lait humain, l'HGMF II [131].

Une partie de l'activité de stimulation de la croissance cellulaire du colostrum bovin, qui est vingt fois supérieure à celle du lait, est retrouvée dans les fractions de chromatographie correspondant à l'insuline, hormone qui inhibe la dégradation intracellulaire des protéines dans les cellules en culture. Toutefois, d'autres fractions de chromatographie sont également actives [15].

Quelques années plus tard, des polypeptides qui possèdent les propriétés de l'insuline: l'insulin-like growth factor 1 et 2 (IGF1 et IGF2) ont été mis en évidence dans le colostrum bovin [16]. L'IGF1 dépourvu de ses trois acides aminés $\mathrm{N}$-terminaux se révèle 5 à 10 fois plus actif que l'IGF1 natif, qu'il soit de synthèse ou préparé à partir du colostrum bovin $[16,30,31]$. Sa concen- tration dans le colostrum est voisine de $0,5 \mathrm{ng} \cdot \mathrm{mL}^{-1}[145]$ et est très augmentée dans le lait de quartiers à mammites clinique ou subclinique [79]. Sa séquence est identique à celle de l'IGF1 humain. La séquence de 1'IGF2 ne differe que par trois acides aminés de la séquence de l'IGF2 humaine, ce qui suffit cependant pour ne conserver que $10 \%$ de réactivité immunologique croisée [46]. Des récepteurs à haute affinité $(0,5$ à $1,5 \times$ $10^{9} \mathrm{~L} \cdot \mathrm{mol}^{-1}$ ) pour l'IGF1 et l'IGF2 ont été mis en évidence dans la glande mammaire de brebis, particulièrement pendant la période de gestation [24].

Un polypeptide très basique de $35 \mathrm{kDa}$, baptisé colostric basic growth factor (CBGF), est présent en forte concentration dans le colostrum et absent du lait de vache, de chèvre et de brebis [13].

Un polypeptide de $38 \mathrm{kDa}$, riche en proline $(22 \%)$, capable de stimuler la synthèse d'anticorps contre des globules rouges de mouton chez la souris a été isolé à partir du colostrum ovin et particulièrement étudié [51]. De $38 \mathrm{kDa}$, ce polypeptide baptisé PRP (proline rich polypeptide) a ensuite été estimé à $18 \mathrm{kDa}$, et s'est révélé constitué de sous-unités de $6 \mathrm{kDa}$ liées de façon non covalente [52, 153]. Son action sur la maturation des thymocytes murins en cellules $T$ helper ou T suppressives [158, 159] s'est révélée contenue dans un nonapeptide obtenu par digestion chymotrypsique et plus particulièrement dans les six derniers acides aminés de l'extrêmité carboxy-terminale [53]. Ce PRP a, de plus, la capacité d'induire la multiplication et la différenciation des lymphocytes B en culture, d'une façon comparable à celle du LPS de Salmonella typhosa à l'exception du switch des isotypes d'immunoglobulines [55].

Plus récemment, il a été montré que du colostrum lyophilisé, aux concentrations de 0,1 et $1 \mu \mathrm{g} \cdot \mathrm{mL}^{-1}$ dans le milieu de culture, induit une réponse proliférative des lymphocytes humains ; il exerce par contre une activité inhibitrice aux concentrations supérieures (10 et $100 \mu \mathrm{g} \cdot \mathrm{mL}^{-1}$ ). La fraction 
active a une masse moléculaire de $18 \mathrm{kDa}$ et réagit avec un anticorps monoclonal anti$\alpha$-lactalbumine [91].

D'une façon générale, le colostrum bovin stimule la croissance des cellules épithéliales (épithélium intestinal), des hybridomes et des cellules transformées, mais pas celle des fibroblastes, du fait notamment de l'absence de fibronectine $[60,61,100-102$, $114,136]$. Toutefois, il a été montré qu'un extrait de colostrum bovin obtenu par chromatographie d'échanges d'ions et chromatographie en phase inverse stimule la croissance des myoblastes L6 de rat, des fibroblastes de souris (Balb/c 3T3), des cellules BHK de hamster et des cellules rénales, avec la même activité que le sérum de veau foetal [149]. La séparation de cet extrait de colostrum par chromatographie d'exclusion moléculaire révèle la présence de différents composants actifs pour chaque type cellulaire. Par ailleurs, le colostrum chauffé conserve son activité de stimulation de la croissance des fibroblastes de souris $\mathrm{CH}_{3}$ [2].

Les inhibiteurs des protéases, dont nous avons décrit la présence dans le colostrum (cf. § 3.3), peuvent également jouer un rôle important et sous-estimé dans les activités stimulantes du colostrum sur la multiplication cellulaire [15].
Le lait et ses sous-produits contiennent également de nombreuses molécules actives en culture cellulaire, certaines d'entre elles, comme la $\beta$-lactoglobuline, pouvant être en concentration plus élevée dans le colostrum. Toutefois, leur description sort du domaine de cette synthèse et le lecteur pourra se référer à une revue récente [38].

\subsection{Vitamines, minéraux majeurs et oligo-éléments}

Le colostrum contient de nombreuses vitamines dont les concentrations sont généralement cinq à dix fois supérieures à celles du lait $[59,64,72]$. Ainsi la concentration de carotène dans le colostrum est de $50-300 \mu \mathrm{g} \cdot \mathrm{g}^{-1}$ de matière grasse, pour 9 à 21 dans le lait [95]. Pour la vitamine E ( $\alpha$-tocophérol), les concentrations dans le colostrum et dans le lait sont, selon les auteurs, respectivement de 1,9 et $0,3 \mu \mathrm{g} \cdot \mathrm{mL}^{-1}$ [42] ou 11,1 et $1,7 \mu \mathrm{g} \cdot \mathrm{mL}^{-1}$ [90].

Pour les minéraux et oligoéléments (tableau II), le rapport de concentration le plus élevé entre le colostrum et le lait (rapport 19) est observé pour le fer [59]. Les taux de plomb, cobalt, nickel et iode sont deux à cinq fois plus élevés dans le colostrum que dans le lait [83]. Le calcium, le magnésium, le phosphore et le sodium dimi-

Tableau II. Évolution des minéraux et oligoéléments des sécrétions lactées pendant les $12 \mathrm{j}$ post-partum (d'après Kincaid et Cronrath [59]).

Tableau II. Changes in minerals and trace elements in milk during the first $12 \mathrm{~d}$ post-partum (adapted from Kincaid et Cronrath [59]).

Temps après la mise-bas (h)

\begin{tabular}{llllll} 
& 1 & 25 & 61 & 144 & 288 \\
\hline $\mathrm{Ca}, \mathrm{g} \cdot \mathrm{L}^{-1}$ & 1,6 & 1,0 & 1,0 & 0,9 & 0,1 \\
$\mathrm{P}, \mathrm{g} \cdot \mathrm{L}^{-1}$ & 1,7 & 1,0 & 0,9 & 0,8 & 0,1 \\
$\mathrm{Cu}, \mathrm{ppm}$ & 0,39 & 0,34 & 0,31 & 0,27 & 0,03 \\
$\mathrm{Fe}, \mathrm{ppm}$ & 1,9 & 1,1 & 0,9 & 0,8 & 0,1 \\
$\mathrm{Mn}, \mathrm{ppm}$ & 0,09 & 0,06 & 0,08 & 0,08 & 0,02 \\
$\mathrm{Zn}, \mathrm{ppm}$ & 23,7 & 12,1 & 8,7 & 7,2 & 5,3 \\
\hline
\end{tabular}


nuent globalement d'un facteur 2 entre la première et la huitième traite. Seul le potassium augmente légèrement entre ces deux traites [80].

\section{4. ÉVOLUTION DES PROTÉINES SOLUBLES DANS LES LAITS DE MAMMITES, DE FIN DE LACTATION ET AU COURS DU TARISSEMENT}

Les composants que nous avons décrits sont en concentration plus élevée dans le colostrum que dans le lait. Si certains d'entre eux, comme les IgG $_{1}$ ou la transferrine, sont concentrés sélectivement à partir du sang, la grande majorité en dérivent du fait d'une perméabilité accrue de l'épithélium mammaire pendant la phase colostrale. Cette augmentation de perméabilité peut également s'observer dans les cas de mammites et pendant la phase d'involution utérine ; on observe alors un passage de protéines du sang vers le lait mais également l'inverse. Avant de choisir un marqueur idéal, caractéristique du colostrum, il est donc important d'examiner les connaissances disponibles sur l'évolution des protéines solubles du lait lors de mammites ainsi que pendant la fin de la lactation et durant l'involution de la mamelle.

\section{1. Évolution au cours des mammites}

Les taux de $\beta$-lactoglobuline et d' $\alpha$-lactalbumine ne sont pas significativement modifiés lors d'infections mammaires [19, $115]$ ou sont légèrement diminués $[9,40$, 69].

Plusieurs équipes ont mis en évidence une augmentation des taux d'immunoglobulines et de la sérum-albumine dans les laits de mammites $[9,20,69]$. Les taux d' $I g G_{1}$ et d' $\mathrm{IgG}_{2}$ ne sont cependant guère modifiés lors d'infections naturelles de la mamelle par des pathogènes mineurs, et doublent en moyenne lors d'infections par des pathogènes majeurs $[17,18]$. Des résultats du même ordre de grandeur ont été observés pour des inflammations expérimentales de la mamelle, avec une corrélation signicative entre les taux d' $\mathrm{IgG}_{1}, \mathrm{IgG}_{2}, \mathrm{IgA}$ et IgM et ceux de l'albumine, suggérant un transfert passif de ces immunoglobulines pendant l'inflammation [37]. Un doublement des taux d'albumine et un triplement des taux d'IgG dans les laits positifs au Wisconsin Mastitis Test a été noté [115].

En début d'infection expérimentale modérée de la mamelle par des colibacilles, un passage des $\mathrm{IgG}_{1}, \mathrm{IgG}_{2}$ et $\mathrm{IgM}$ du sang vers le lait similaire à celui de l'albumine a été mis en évidence [112]. Les concentrations d'IgM se sont révélées ensuite plus élevées que celles attendues sur la base d'un simple transfert passif. Lors d'infections expérimentales plus sévères, obtenues par inoculation de colibacilles ou injection d'endotoxine, les taux d'IgG peuvent atteindre des valeurs plus élevées, mais pendant une durée très courte $[41,98]$ (figures 4 et 5),

L'augmentation de la sérum-albumine lors de mammites a conduit certains auteurs à proposer le dosage de cette protéine par immunodiffusion radiale comme moyen de diagnostic des infections mammaires [ 32 , 146]. Cependant, d'autres auteurs trouvent des augmentations très modérées de la sérum-albumine lors de mammites : $0.24 \mathrm{mg} \cdot \mathrm{mL}^{-1}$ dans les laits de mammites à pathogènes mineurs et $0,28 \mathrm{mg} \cdot \mathrm{mL}^{-1}$ pour les laits à pathogènes majeurs pour $0,2 \mathrm{mg} \cdot \mathrm{mL}^{-1}$ dans le lait issu de mamelles saines [106]. Dans les mammites expérimentales obtenues par injection de colibacilles ou d'endotoxine colibacillaire, on observe des augmentations plus importantes de l'albumine, pouvant atteindre $20 \mathrm{mg} \cdot \mathrm{mL}^{-1}$, mais ces augmentations ne durent généralement que quelques heures à quelques jours [41, 98, 112]. Même pour des quantités relativement faibles d'endotoxine $(10 \mu \mathrm{g})$ les taux d'albumine passent de 0,3 à 


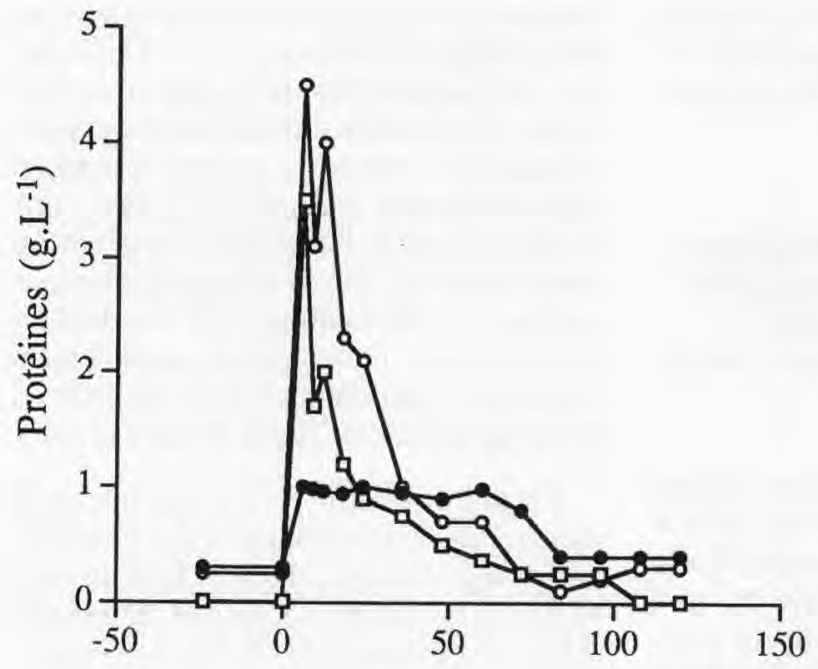

Heures

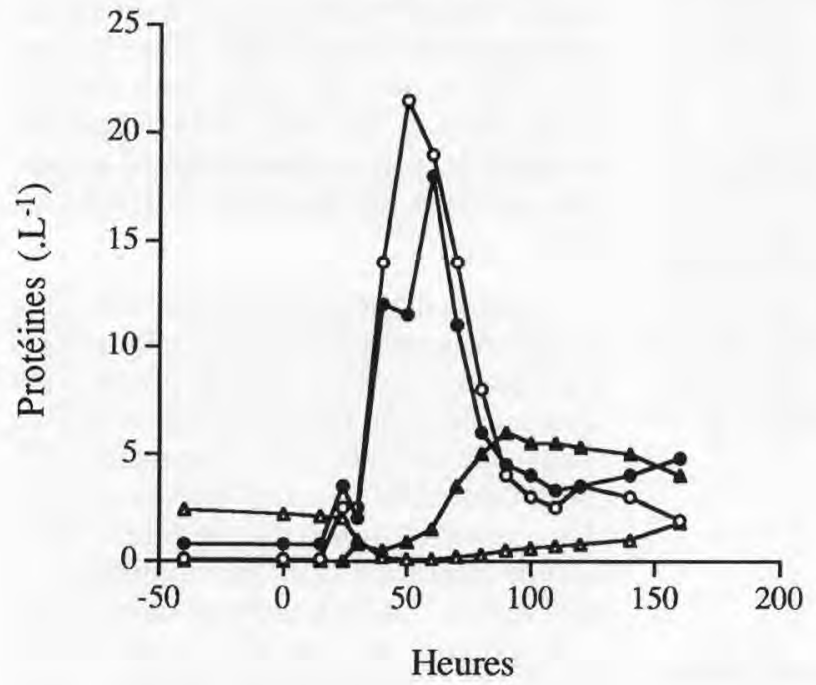

Figure 4. Variation de la concentration des $\mathrm{IgG}_{1}(\mathbf{O})$, $\mathrm{IgG}_{2}(\square)$ et de l'albumine (O) dans le lait de vaches ayant reçu une injection de $100 \mu \mathrm{g}$ d'endotoxine d' $E$. coli dans la mamelle (d'après Ost et al. [98]). Le temps 0 correspond au moment de l'injection de l'endotoxine.

Figure 4. Changes in the concentration of $\operatorname{IgG}_{1}(\bullet)$, $\mathrm{IgG}_{2}(\square)$ and albumin $(O)$ in the milk of cows after injection of $100 \mu \mathrm{g}$ endotoxin from $E$. coli in the udder at time 0 (adapted from Ost et al. [98]).

Figure 5. Variation de la concentration des IgG ( ), de l'albumine $(\mathrm{O})$, de la lactoferrine $(\boldsymbol{\Delta})$ et de l' $\alpha$-lactalbumine $(\Delta)$ chez des vaches expérimentalement infectées par $E$. coli (d'après Harmon et al. [41]). Le temps 0 correspond au moment de l'injection d'E. coli.

Figure 5. Changes in the concentration of $\operatorname{IgG}(\boldsymbol{)})$, albumin $(\mathrm{O})$, lactoferrin $(\boldsymbol{\Delta})$ and $\alpha$-lactalbumine $(\triangle)$ in cows experimentally infected by $E$. coli $i$ at time 0 (adapted from Harmon et al. [41]).
$2,3 \mathrm{mg} \cdot \mathrm{mL}^{-1}$ dès la première traite qui suit l'injection, puis ils redescendent rapidement à leur valeur de base : $1,2 \mathrm{mg} \cdot \mathrm{mL}^{-1}$ à la deuxième traite, 0,75 à la troisième et $0,5 \mathrm{mg} \cdot \mathrm{mL}^{-1}$ à la quatrième traite [132].

Les taux de transferrine ne sont pas modifiés lors d'infections de la mamelle par des pathogènes mineurs, mais ils doublent pour atteindre $0,05 \mathrm{mg} \cdot \mathrm{mL}^{-1}$ en cas de patho- gènes majeurs [113]. La lactoferrine passe de 0,08 à $0,11 \mathrm{mg} \cdot \mathrm{mL}^{-1}$ en cas d'atteinte de la mamelle par des pathogènes mineurs et à $0,18 \mathrm{mg} \cdot \mathrm{mL}^{-1} \mathrm{~s}^{\prime}$ il s'agit de pathogènes majeurs [113]. Là encore, dans les inflammations aiguës expérimentales les augmentations sont plus importantes, pouvant atteindre $0,7 \mathrm{mg} \cdot \mathrm{mL}^{-1}[132]$ à $6-7 \mathrm{mg} \cdot \mathrm{mL}^{-1}$ [41] pendant quelques heures. 
Les concentrations des protéines de l'inflammation, comme l'haptoglobine, la céruloplasmine, l' $\alpha_{1}$-glycoprotéine (orosomucoïde) ainsi que celles de l' $\alpha_{1}$-antitrypsine et de l'inhibiteur de l' $\alpha_{1}$-proteinase augmentent non seulement dans le lait mais également dans le sérum des vaches atteintes de mammites [22, 44, 87]. Les écarts les plus importants sont observés pour l'haptoglobine dont les taux passent d'un niveau non décelable à des valeurs comprises entre 13 et $127 \mathrm{mg}$ d'hémoglobine fixable/ $100 \mathrm{~mL}$ de lait [22].

Dans les laits de mammites, les taux d' $\alpha_{2}$-macroglobuline augmentent de façon très marquée : ils passent de $4,5 \mu \mathrm{g} \cdot \mathrm{mL}^{-1}$ à 48,71 et $89 \mu \mathrm{g} \cdot \mathrm{mL}^{-1}$ pour des laits classés respectivement en catégorie,+++ et +++ au Californian Mastitis Test [103].

Les taux de N-acétyl- $\beta$-D-glucosaminidase sont également augmentés dans les laits de mammites et une valeur supérieure à 2,9 unités indique une mammite pour tout échantillon de lait prélevé entre 4 et $280 \mathrm{j}$ post-partum [104].

Un anticorps monoclonal a été produit contre une protéine non identifiée de $23,5 \mathrm{kDa}$ qui est présente en forte concentration dans les laits de mammites. Un dosage de cette protéine par technique Elisa appliqué à 2612 laits de quartiers à mammites subcliniques a montré une bonne correlation avec le comptage de cellules [4].
La perméabilité accrue de la mamelle au cours des mammites n'est pas à sens unique : si des protéines sanguines passent dans le lait, l'inverse se produit également et des protéines du lait peuvent passer dans le sang. Ainsi le dosage de la $\beta$-lactoglobuline et de l' $\alpha$-lactalbumine sanguine a été proposé pour donner une mesure indirecte de l'état de santé de la mamelle. Il a été en effet montré que le taux d' $\alpha$-lactalbumine dans le sang était corrélé avec le nombre de cellules somatiques dans le lait $(r=0,60)$ et que la concentration moyenne d' $\alpha$-lactalbumine augmentait même pour de faibles concentrations de cellules $\left(25\right.$ à $\left.250 \times 10^{3}\right)$ [88]. Lors d'une inflammation aiguë déclenchée par l'injection d'endotoxine d' $E$. coli, la concentration sanguine d' $\alpha$-lactalbumine passe de 80 à $1909 \mathrm{ng} \cdot \mathrm{mL}^{-1}$ et celle de caséine $\alpha_{\mathrm{S} 1}$ de 0 à $1231 \mathrm{ng} \cdot \mathrm{mL}^{-1}$. Les valeurs retrouvent leur niveau de base $96 \mathrm{~h}$ plus tard.

\section{2. Évolution en fin de la lactation}

Dans le tableau III sont synthétisées les données concernant les taux d' $\mathrm{IgG}_{1}, \mathrm{IgG}_{2}$, $\beta$-lactoglobuline, $\alpha$-lactalbumine, sérumalbumine, lactoferrine et transferrine, mesurées dans le lait de vaches à 30 et $270 \mathrm{j}$ postpartum par l'équipe de Poutrel [17-19, 106, 113]. On assiste à une augmentation des taux des $\operatorname{IgG}_{1}$, de la $\beta$-lactoglobuline, de

Tableau III. Concentration ( $\mathrm{g} \cdot \mathrm{L}^{-1}$ ) de quelques protéines solubles du lait de vache aux $30^{\mathrm{e}}$ et $270^{\mathrm{e}} \mathrm{j}$ de lactation selon Rainard et al. [113], Poutrel et al. [106], Caffin et al. [18, 19] et Caffin et Poutrel [17]. $\beta$-Lg: $\beta$-lactoglobuline ; $\alpha$-La : $\alpha$-lactalbumine.

Tableau III. Concentration (g. $\cdot \mathrm{L}^{-1}$ ) of soluble proteins in cow milk at days 30 and 270 of lactation, according to Rainard et al. [113], Poutrel et al. [106], Caffin et al. [18, 19] and Caffin et Poutrel [17]. $\beta$-Lg: $\beta$-lactoglobulin; $\alpha$-La: $\alpha$-lactalbumin.

\begin{tabular}{lccccccc}
\hline & $\mathrm{IgG}_{1}$ & $\mathrm{IgG}_{2}$ & $\beta$-Lg & $\alpha$-La & Albumine & Lactoferrine & Transferrine \\
\hline j 30 & 0,38 & 0,018 & 4,15 & 1,54 & 0,17 & 0,03 & 0,025 \\
j 270 & 0,6 & 0,018 & 5,36 & 1,36 & 0,22 & 0,15 & 0,035 \\
Test $t$ & $p<0,001$ & NS & $p<0,001$ & $p<0,001$ & $p<0,01$ & $p<0,02$ & $p<0,03$ \\
\hline
\end{tabular}


l'albumine, de la lactoferrine et de la transferrine, et à une baisse du taux d' $\alpha$-lactalbumine. Seuls les taux d' $\mathrm{IgG}_{2}$ restent stables.

La concentration des IgA et des IgM remonte également en fin de lactation [36].

Le stade de lactation a également un effet sur certaines enzymes du lait. Ainsi, les concentrations de $\mathrm{N}$-acetyl- $\beta$-D-glucosaminidase sont élevées en début de lactation, diminuent au milieu et remontent en fin de lactation [154].

\section{3. Évolution pendant l'involution de la mamelle}

À partir du tarissement, on assiste à de profondes perturbations de la composition des sécrétions lactées, composition qui se rapproche progressivement de celle du colostrum. L'une des modifications les plus remarquables, en dehors de celles qui touchent les IgG, concerne la lactoferrine. Sa concentration s'élève dès les 2 à 4 premiers jours qui suivent l'arrêt de la traite, pour augmenter ensuite régulièrement d'environ $1,15 \mathrm{mg} \cdot \mathrm{mL}^{-1}$ par jour durant les $14-21$ premiers jours de l'involution et atteindre une valeur maximale de $20 \mathrm{mg} \cdot \mathrm{mL}^{-1}$ après trois à quatre semaines d'involution [151]. Chez certaines vaches, les taux plafonnent à moins de $10 \mathrm{mg} \cdot \mathrm{mL}^{-1}$ dès le $10^{\mathrm{e}} \mathrm{j}$ d'involution ; chez d'autres des concentrations atteignant 75 à $100 \mathrm{mg} \cdot \mathrm{mL}^{-1}$ ont été enregistrées. Ainsi, la lactoferrine, bien que protéine minoritaire du lactosérum dans le courant de la lactation, devient la protéine majoritaire des sécrétions de mamelles complètement involuées [151].

Des résultats récemment publiés montrent que les concentrations de plasminogène et de plasmine augmentent rapidement dans la mamelle dès le tarissement [3]. L'accélération de l'involution de la mamelle par l'injection d'œstrogènes (15 mg d'œestradiol- $\beta$ ) $4 \mathrm{j}$ avant le tarissement entraîne une augmentation plus importante des taux de plasminogène et de plasmine mais avec une chute du rapport plasminogène/plasmine consécutive à l'activation du plaminogène [3]. Cette observation a conduit les auteurs à suggérer une implication du système plasmine-plasminogène dans l'involution des tissus mammaires chez les bovins.

D'autres protéines, au contraire, voient leur concentration diminuer pendant l'involution de la mamelle. Il en est ainsi de la protéine du stress thermique de $90 \mathrm{kDa}$ (HSP90) décrite récemment [148]. La concentration de cette protéine, exprimée en pourcentage des protéines cytoplasmiques passe de $1,25 \pm 0,18$ dans le courant de la lactation à $0,54 \pm 0,22$ durant l'involution.

Du fait de la perméabilité accrue de la barrière sanguine pendant la phase d'involution mammaire, les concentrations sanguines d' $\alpha$ lactalbumine et de $\beta$-lactoglobuline augmentent pendant les trois derniers mois de gestation, passant de 70 et $20 \mathrm{ng} \cdot \mathrm{mL}^{-1}$ respectivement à 1100 et $460 \mathrm{ng} \cdot \mathrm{mL}^{-1}$ au moment du part. Les concentrations chutent ensuite rapidement pour atteindre respectivement 140 et $25 \mathrm{ng} \cdot \mathrm{mL}^{-1}$ à la deuxième semaine post-partum [85]. L'augmentation de la concentration sérique d' $\alpha$ lactalbumine est plus importante chez les vaches laitières que chez les allaitantes, avec des taux à la mise bas de 720 et $150 \mathrm{ng} \cdot \mathrm{mL}^{-1}$ respectivement [39]. La concentration sanguine de $\beta$-lactoglobuline mesurée chez des génisses en fin de gestation s'est révélée corrélée avec la quantité de lait $(r=0,60)$ et de matières grasses $(\mathrm{r}=0,60)$ produites pendant les deux lactations suivantes [86]. De ce fait, le dosage du taux de $\beta$-lactoglobuline sérique chez les génisses gestantes de 26 semaines a été proposé pour la prédiction de la production laitière [85].

\section{4. Évolution chez les vaches non taries}

Une situation intermédiaire entre les laits de fin de lactation (environ $300 \mathrm{j}$ ) et les sécrétions obtenues pendant l'involution de la mamelle doit être considérée : il s'agit 
des laits provenant de vaches laitières dont la traite a été poursuivie pratiquement jusqu'au vélage. Les rares travaux publiés sur ce sujet ont concerné essentiellement la composition chimique globale du lait, les pourcentages des différentes caséines et les conséquences zootechniques et sanitaires de cette pratique $[28,119-122,133,135$, 152]. Parmi les protéines solubles du lait, les données publiées concernent les $\mathrm{IgG}_{1}$ et la plasmine. Les taux d'IgG montent $_{1}$ rapidement pour atteindre des valeurs de $25 \mathrm{mg} \cdot \mathrm{mL}^{-1}$ (vaches primipares) à $40 \mathrm{mg} \cdot \mathrm{mL}^{-1}$ (vaches multipares) dans la semaine qui précède la mise-bas [119]. Un phénomène comparable d'augmentation des taux de plasmine a été observé [27]. Les résultats du dosage de la $\beta$-lactoglobuline, de l' $\alpha$-lactalbumine et de la sérum-albumine montrent également une augmentation progressive de leur concentration (Levieux et al., résultats non publiés).

Le lait obtenu dans les jours qui précèdent la mise-bas a donc les principales caractéristiques du colostrum sans toutefois en porter le nom, et ne peut en être différencié. L'addition d'un tel lait dans le lait de tank peut donc poser au technologue les mêmes problèmes que l'addition du colostrum, sans toutefois être interdite par la législation.

\section{CHOIX DU MEILLEUR MARQUEUR DE LA PRÉSENCE DE COLOSTRUM DANS LES LAITS DE GRAND MÉLANGE}

Dans le tableau $I V$ sont résumées les données quantitatives disponibles sur les composants précédemment passés en revue qui ont un rapport de concentration entre le colostrum et le lait $=50$.

Parmi les six protéines candidates au rôle de marqueur, la lactoferrine peut être éliminée du fait de l'importance de ses variations en fonction du stade physiologique de lactation [113]. L' $\alpha_{1}$-glycoprotéine, tout comme les autres protéines de la réaction inflammatoire telles que l'haptoglobine, la céruloplasmine ou l'inhibiteur de l' $\alpha_{1}$-protéinase, peut également être éliminée puisque sa concentration augmente lors de mammites ou d'autres types de réactions inflammatoires [44].

L' $\alpha_{2}$-macroglobuline pourrait être un marqueur intéressant, car son poids moléculaire élevé la rend théoriquement moins susceptible de franchir la barrière capillaire que les IgG ou l'albumine. De plus, ses propriétés d'inhibiteur enzymatique peuvent lui attribuer un rôle dans les propriétés technologiques anormales du colostrum. Toutefois, la variabilité de la concentration de cette protéine dans le colostrum et le lait est

Tableau IV. Synthèse des données quantitatives sur les protéines dont le rapport de concentration entre le colostrum de première traite et le lait est $\geq 50$.

Tableau IV. Quantitative data for proteins having a ratio of their concentration in colostrum $/ \mathrm{milk} \geq 50$.

\begin{tabular}{|c|c|c|c|}
\hline & \multicolumn{2}{|c|}{ Concentration $\left(\mathrm{g} \cdot \mathrm{L}^{-1}\right)$} & \multirow{2}{*}{$\begin{array}{c}\text { Rapport } \\
\text { Colostrum/lait }\end{array}$} \\
\hline & Colostrum & Lait & \\
\hline $\mathrm{IgG}_{1}$ & 60 & 0,5 & 120 \\
\hline IgM & 4,0 & 0,04 & 100 \\
\hline Lactoferrine & 4,5 & 0,09 & 50 \\
\hline Transferrine & 1,03 & 0,02 & 52 \\
\hline$\alpha_{1}$-glycoprotéine & 1,65 & 0,017 & $97 *$ \\
\hline$\alpha_{2}$-macroglobuline & 0,4 & 0,005 & 80 \\
\hline
\end{tabular}

* Rapport théorique extrapolé à partir de la cinétique de décroissance décrite par Mesa et al. [92].

* Theoretical ratio extrapolated from the kinetic described by Mesa et al. [92]. 
actuellement insuffisamment documentée et les variations de sa concentration pendant les mammites paraissent importantes [103, 104].

Il reste donc deux marqueurs à départager: les IgM et les IgG. Ces deux protéines ont la même activité biologique, la protection de l'organisme contre les infections microbiennes. Elles sont toutes deux thermosensibles et ne peuvent nuire aux propriétés technologiques du lait que par leur présence dans le lait à concentration élevée, ce qui est le cas des $\operatorname{IgG}$ puisque leur concentration dans le lait et le colostrum est respectivement 12 à 15 fois plus élevée que celle des IgM et dépasse rapidement, dans le lait, le $\mathrm{g} \cdot \mathrm{L}^{-1}$ pour des ajouts de colostrum supérieures à $1 \%$. Les IgG sont donc les principales responsables du surpaiement du lait à la qualité protéique lors d'une contamination par du colostrum. Par ailleurs, contrairement aux IgG, il n'est pas possible de se procurer des IgM bovines dans le commerce et la conservation de solutions diluées de ces immunoglobulines est problématique. Enfin, les IgG sont certainement les protéines dont les variations de concentration dans le colostrum et le lait sont les plus documentées. Leur utilisation fréquente comme marqueur de la présence de colostrum dans les laits de mélange est donc parfaitement justifiée.

\section{DOSAGE ET TAUX ADMISSIBLE DU MARQUEUR}

\subsection{Méthodes de dosage des IgG du lait}

Différentes techniques peuvent être utilisées pour le dosage des protéines du lait. Les techniques physiques comme l'électrophorèse sur gel de polyacrylamide $[96,115$, 116], sur acétate de cellulose [23] ou l'HPLC $[99,116]$ sont insuffisamment précises pour le dosage des IgG du fait de l'hétérogénéité de la charge électrique de ces protéines et de leur faible concentration dans le lait dès que l'on s'éloigne de la misebas. Par ailleurs, le coût analytique de ces techniques est élevé.

Les techniques immunonéphélométriques nécessitent la coagulation du lait et la préparation de lactosérums parfaitement limpides, filtrés à $0,2 \mu \mathrm{m}$, ce qui alourdit le protocole et augmente le coût analytique [70]. L'immunonéphélométrie particulaire, du fait de sa plus grande sensibilité, permet dans certains cas l'analyse d'échantillons de lait très dilués, et donc d'éviter les étapes de coagulation et de filtration [48].

Les techniques Elisa, bien que souvent longues en temps de manipulation, sont adaptées aux grandes séries d'échantillons et plus particulièrement aux protéines présentes en faible concentration $\left(<\mu \mathrm{g} \cdot \mathrm{mL}^{-1}\right)$. Pour doser les IgG dans les laits de grand mélange il faut donc prévoir une dilution des échantillons de l'ordre du 1/1000 voire $1 / 10000$ et pour les colostrums une dilution supérieure ou égale au $1 / 100000$, ce qui alourdit les manipulations. De plus, des concentrations d'IgG systématiquement inférieures à celles obtenues en immunodiffusion radiale, ont été trouvées en Elisa de type sandwich, ce qui a fait suggérer la possibilité d'une interférence par un composant non identifié du lait [65].

La grande majorité des travaux précédemment cités concernant la composition protéique du colostrum ont été réalisés en utilisant la technique d'immunodiffusion radiale (IDR) [84] comme technique de dosage. Dans cette technique, quelques $\mu \mathrm{L}$ d'échantillon sont déposés dans un trou percé dans une gélose qui contient un antisérum approprié, puis mis à diffuser pendant quelques heures (lecture rapide) ou une nuit. Après diffusion, il suffit de mesurer le diamètre du précipité circulaire apparu dans la gélose, diamètre qui est linéairement proportionnel à la racine carrée de la concentration de la protéine dans l'échantillon. $\mathrm{La}$ limite de détection, de l'ordre du $\mu \mathrm{g} \cdot \mathrm{mL}^{-t}$ (au lieu du ng. $\mathrm{mL}^{-1}$ pour l'Elisa) est suffisante pour le dosage de la majorité des pro- 
téines du lait. De plus, l'IDR permet d'analyser les échantillons de lait ou de colostrum entiers simplement dilués, condition recommandée par certains auteurs [29] pour le dosage des IgG. Le développement de cette technique a été longtemps limité par son absence d'automatisation et la mesure manuelle fastidieuse des diamètres des précipités. Cet obstacle a été levé par l'automatisation de la dilution au 1/10 des échantillons de lait dans des microplaques, des dépôts et de la mesure des diamètres à l'aide d'une caméra vidéo et d'un système peu onéreux d'analyse du signal fourni par la caméra [74].

Le choix de l'antisérum et des IgG utilisées comme référence pour l'étalonnage du dosage conditionne la justesse du dosage $[8,78]$. En effet, le rapport de concentration des $\lg G_{1}$ et $I_{g G_{2}}$ est très différent dans le sérum $(55 / 45)$ et dans le lait $(90 / 10)[15$, 97]. Les IgG commercialisées sont fréquemment purifiées à partir du sérum bovin par chromatographie d'échange d'ions et contiennent essentiellement des $\mathrm{IgG}_{2}$; les antisérums préparés avec ces $\mathrm{IgG}_{2}$ reconnaissent également les $\operatorname{IgG}{ }_{1}$, mais de façon moins intense. Les $\mathrm{IgG}_{1}$ étant largement majoritaires dans le lait, elles seront surestimées si une gamme d'IgG sériques $\left(\mathrm{IgG}_{2}\right)$ est utilisée pour l'étalonnage en immunodiffusion radiale. Ceci explique, en partie, les discordances observées dans la littérature sur les taux normaux d' $\operatorname{IgG}$ du lait [74, 77]. Il est donc conseillé d'utiliser des antisérums du commerce préparés à partir d'IgG ${ }_{1}$ colostrales et d'étalonner le dosage des IgG du lait à partir d'une solution de ces immunoglobulines [474].

\subsection{Taux d'IgG admissible dans un lait normal}

L'établissement d'un tel taux nécessite de définir quelles sont les bornes statistiques de la concentration en IgG d'un lait normal. Pour cela, il faut doser les IgG dans un grand nombre de laits individuels provenant de vaches normales puis simuler quelle serait la moyenne et l'écart type du taux d'IgG d'un mélange en quantité croissante de ces laits après tirage au hasard par un programme informatique. On obtient ainsi, pour un litrage donné, une fourchette du taux d'IgG acceptable, avec un risque d'erreur préalablement défini (figure 6). Une telle approche a été développée dès 1981 à partir de dosages effectués en immunonéphélométrie [54] et récemment réactualisée pour des dosages par immunodiffusion radiale, avec un étalonnage et un antisérum basés sur des IgG1 et un échantillonnage de laits plus important [76].

Au-delà du taux d'IgG acceptable, taux sur lequel un consensus international pourrait être établi, le lait ne répondrait plus à la définition que lui donne la Fédération internationale de laiterie.

Ce taux d'IgG est, bien entendu, différent du taux à partir duquel la présence de colostrum dans un lait peut poser des problèmes technologiques, et pour lequel un consensus serait difficile à obtenir du fait, d'une part, de la grande variété des traitements appliqués au lait et, d'autre part de la faible documentation disponible sur les répercussions technologiques d'un excès d'IgG dans le lait. Il n'y aurait pas de problèmes technologiques si du lait prélevé 5 à $6 \mathrm{j}$ après la mise-bas est ajouté à raison de $10 \%$ à du lait de grand mélange [140] ce qui correspondrait à une concentration en IgG maximale de $0,9 \mathrm{mg} \cdot \mathrm{mL}^{-1}$ [75]. L'addition de $5 \%$ de colostrum de première traite à du lait de grand mélange serait suffisante pour affecter ses propriétés technologiques [50], soit une concentration en IgG de $3,4 \mathrm{mg} \cdot \mathrm{mL}^{-1}[75]$. En Nouvelle-Zélande, le taux d'IgG toléré dans le lait est de $2 \mathrm{mg} \cdot \mathrm{mL}^{-1}$ [62]. L'importance de l'écart entre ces valeurs souligne la nécessité d'études plus poussées sur les conséquences de la présence de colostrum dans le lait de grand mélange, et ce en fonction des différentes technologies appliquées au lait. De telles études pourraient conduire à la défi- 


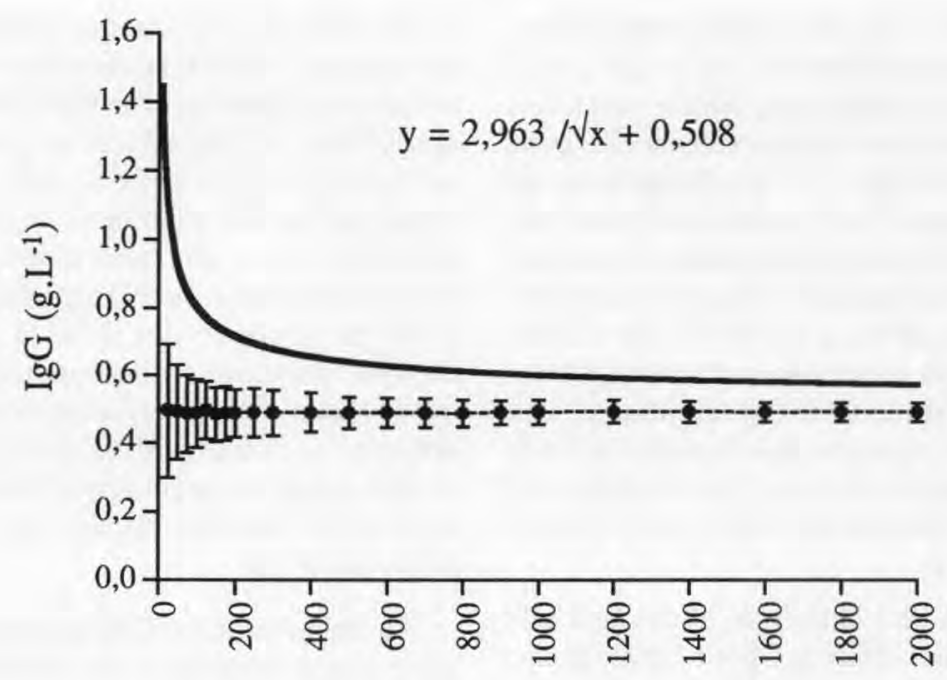

Volume de lait (litres)

Figure 6. Concentrations d' $\mathrm{IgG}_{1}$ trouvées (----) et admissibles $(\longrightarrow)$ (moyenne $\left.+3 \sigma\right)$ pour des simulations de laits de mélange, en fonction du litrage (d'après Levieux et Retière [76]).

Figure 6. Simulation of physiological variations of $\mathrm{IgG}_{1}$ concentration (mean $\pm \mathrm{SD}$ ), $(-)$ and of acceptable $\mathrm{IgG}_{1}$ concentration for normal herd milk (----) as a function of milk quantity (from Levieux and Retière [76]).

nition de différents taux d'IgG acceptables pour le technologue selon l'utilisation qui doit être faite du lait mais également à une estimation plus précise des répercussions économiques de la présence de colostrum dans le lait.

\section{CONCLUSION}

La richesse du colostrum en de nombreux composants et la diversité des propriétés biologiques qui en découlent n'ont pas fini de surprendre car l'inventaire est loin d'être terminé. $\mathrm{Si}$, le colostrum est une véritable potion magique pour le veau de par sa richesse en anticorps, en vitamines et en divers facteurs de croissance, il représente pour le technologue un lait anormal, responsable de problèmes de fabrication, et sa présence dans le lait doit donc être décelée.

Il ressort de cette revue que le meilleur marqueur de la présence de colostrum dans le lait de vache est le taux d'IgG. C'est un marqueur direct puisque sa concentration élevée est connue pour être en partie responsable des problèmes technologiques attribués à la présence de colostrum dans le lait. C'est également un marqueur indirect puisque son évolution dans les jours qui suivent la mise-bas est parallèle à celle d'autres constituants (enzymes et inhibiteurs d'enzymes) pouvant être responsables d'autres problèmes technologiques. Sa concentration élevée autorise son dosage par des techniques simples, rustiques et automatisables, comme l'immunodiffusion radiale. Enfin, c'est la protéine colostrale dont les variations de concentration dans le colostrum et le lait sont les mieux documentées.

Parmi les autres marqueurs qui mériteraient d'être examinés avec plus d'attention, nous retenons l' $\alpha_{2}$-macroglobuline dont les activités d'inhibition enzymatique justifient des études plus poussées quant à 
leur incidence sur la coagulation et la protéolyse des protéines lactées.

Quel que soit le marqueur choisi, il est illusoire de considérer qu'il sera spécifique uniquement de la présence de colostrum au sens légal du terme. En effet, chez les vaches non taries ou taries tardivement, la composition du lait dans les jours ou les semaines qui précèdent la mise-bas est proche de celle du colostrum, mais l'addition de ce lait dans le tank n'est pas répréhensible. Il serait donc préférable, en accord avec la définition de la Fédération internationale de laiterie qui reconnaît uniquement comme lait « le produit de la sécrétion mammaire normale », de s'orienter vers une définition d'un taux d'IgG acceptable pour un lait normal, variable en fonction du litrage livré, et audelà duquel le lait pourra être considéré comme anormal du fait de la présence de colostrum, de lait de mammites ou de fin de lactation. Cette approche permettrait une harmonisation plus aisée des législations nationales.

\section{RÉFÉRENCES}

[1] Abd El-Gawad I.A., El-Sayed E.M., Mahfouz M.B., Abd El-Salam A.M., Changes of lactoferrin concentration in colostrum and milk from different species, Egyp. J. Dairy Sci. 24 (1996) 297-308,

[2] Aranda P.L., Sanchez L., Perez M.D., Calvo M., Growth-promoting activity in bovine milk on a murine fibroblastic cell line and effect of heat treatment, Int. Dairy J. 6 (1996) 1-11.

[3] Athie F., Bachman K.C., Head H.H., Hayen M.J., Wilcox C.J., Milk plasmin during bovine mammary involution that has been accelerated by estrogen, J. Dairy Sci. 80 (1997) 1561-1568.

[4] Ball H.J., Finlay D., Mackie D.P., Greer D., Pollock D., McNair J., Application of a monoclonal antibody-based enzyme-linked immunosorbent assay for detection of an inflammatory response antigen in subclinical mastitic milk samples, J. Clin. Microbiol. 29 (1991) 1625-1628.

[5] Ballard F.J., Nield M.K., Dahlenburg G.W., Wallace J.C., The relationship between the insulin content and inhibitory effects of bovine colostrum on protein breakdown in cultured cells J. Cell. Physiol. 110 (1982) 249-254.

[6] Ballard F.J., Francis G.L., Ross M., Bagley C.J., May B., Wallace J., Natural and synthetic forms of insulin-like growth factor-1 (IGF-1) and the potent derivative, destripeptide IGF-1: biological activities and receptor binding, Biochem. Biophys. Res. Commun. 149 (1987) 398-404.

[7] Bezkorovainy A., Comparative study of the acid glycoproteins isolated from bovine serum, colostrum, and milk whey, Arch. Biochem. Biophys. 110 (1965) 558-567.

[8] Bockhout B.A., Divergent results in radial immunodiffusion with antisera differing in precipitation properties with respect to individual immunoglobulin subclasses. I, The antigen factor. II, The antiserum factor, J. Immunol. Methods 7 (1975) 187-210.

[9] Bortree A.L., Carroll E.J., Schalm O.W., Whey protein patterns of milk from cows with experimentally produced mastitis, J. Dairy Sci. 45 (1962) 1465-1470.

[10] Brandon M.R., Watson D.L., Lascelles A.K. The mechanism of transfer of immunoglobulin into mammary secretion of cows, Aust. J. Exp. Biol. Med. Sci. 49 (1971) 629-633.

[11] Braun J.P., Tainturier D., Laugier C., Benard P., Thouvenot J.P., Rico A.G., Early variation of blood plasma gamma-glutamyl transferase in newborn calves. A test of colostrum intake J. Dairy Sci. 65 (1982) 2178-2181.

[12] Brock J.H., Pineiro A., Lampreave F., Bactericidal and haemolytic activity of complement in bovine colostrum and serum: effect of proteolytic enzymes and ethylene glycol tetraacetic acid (EGTA), Ann. Immunol. 126 (1975) $434-446$.

[13] Brown K.D., Blakeley D.M., Partial purification and characterization of a growth factor present in goat colostrum, Biochem. J. 219 (1984) 609-617.

[14] Burton J.L., Kennedy B.W., Burnside E.B., Wilkie B.N., Burton J.H., Variation in serum concentrations of immunoglobulins $\mathrm{G}, \mathrm{A}$ and $\mathrm{M}$ in Canadian Holstein-Friesian calves, J. Dairy Sci. 72 (1989) 135-149.

[15] Butler J.E., A concept of humoral immunity among ruminants and an approach to its investigation, in: J.E. Butler (éd.), The ruminant immune system, Plenum Press, NY, 1981. pp. 3-55.

[16] Butler J.E, Winter A.J, Wagner G.G., Symposium: bovine immune system, J. Dairy Sci. 54 (1971) 1309-1314.

[17] Caffin J.P., Poutrel B., Physiological and pathological factors influencing bovine immunoglobulin G2 concentration in milk, J. Dairy Sci. 71 (1988) 2035-2043.

[18] Caffin J.P., Poutrel B., Rainard P., Physiologi$\mathrm{cal}$ and pathological factors influencing bovine immunoglobulin Gl concentration in milk J. Dairy Sci. 66 (1983) 2161-2166.

[19] Caffin J.P., Poutrel B., Rainard P., Physiologi$\mathrm{cal}$ and pathological factors influencing bovine $\alpha$-lactalbumin and $\beta$-lactoglobulin concentrations in milk, J. Dairy Sci. 68 (1985) 1087-1094. 
[20] Carroll E.J., Schalm O.W., Lasmanis J., Experimental coliform (Acrobacter aerogenes) mastitis: Distribution of whey proteins during the early acute phase, J. Dairy Sci. 46 (1963) 1236-1240.

[21] Chillard Y., Variations physiologiques des activités lipasiques et de la lipolyse spontanée dans les laits de vache, de chèvre et de femme : revue bibliographique, Lait 62 (1982) 126-154.

[22] Conner J.G., Eckersall P.D., Doherty M., Douglas T.A., Acute phase response and mastitis in the cow, Res. Vet. Sci. 41 (1986) 126-128.

[23] Desmukh A.R., Donker J.D., Addis P.B., Jenness R., Cellulose acetate and polyacrylamide gel electrophoresis for quantification of milk protein fractions, J. Dairy Sci. 72 (1989) 12-17.

[24] Disenhaus C., Belair L., Djiane J., Caractérisation et évolution physiologique des récepteurs pour les « insulin-like growth factors * I et II (IGFs) dans la glande mammaire de brebis, Reprod. Nutr. Develop. 28 (1988) 241-252.

[25] Dixon F.J., Weigle W.O., Vasquez J.J., Metabolism and mammary secretion of serum proteins in the cow, Lab. Invest. 10 (1961) 216-236.

[26] Dupont D., Bailly C., Grosclaude J., Collin J.C., Differential titration of plasmin and plasminogen in milk using sandwich Elisa with monoclonal antibodies, J. Dairy Res. 64 (1997) 77-86.

[27] Dupont D., Remond R., Collin J.C., Elisa determination of plasmin and plasminogen in milk of individual cows managed without the dry period, Milchwissenschaft, 53 (1998) 62-69.

[28] Enevoldsen C., Sorensen J.T., Effects of dry period length on clinical mastitis and other major clinical health disorders, J. Dairy Sci. 75 (1992) 1007-1014.

[29] Fleenor W.A., Stott G.H., Single radial immunodiffusion analysis for quantitation of colostral immunoglobulin concentration, J. Dairy Sci. 64 (1981) $740-747$.

[30] Francis G.L., Read L.C., Ballard F.J., Bagley C.J., Upton F.M., Gravestock P., Wallace J.C., Purification and partial sequence analysis of insulinlike growth factor-1 from bovine colostrum., Biochem. J. 233 (1986) 207-213.

[31] Francis G.L., Upton F.M., Ballard F.J., McNeil K.A., Wallace J.C., Insulin-like growth factor 1 and 2 in bovine colostrum. Sequences and biological activities compared with those of a potent truncated form, Biochem. J. 251 (1988) 95-103.

[32] Giesecke W.H., Viljoen M.H., The diagnosis of subclinical mastitis in lactating cows: a comparison of cytological methods and a monovalent radial immunodiffusion test, Onderstepoort J. Vet. Res. 41 (1974) 51-74.

[33] Gooden J.M., Lascelles A.K., Factor in colostrum causing mobilization of free fatty acid in newborn calves, Aust. J. Exp. Biol. Med. Sci. 49 (1971) 635-638.
[34] Groves M.L., Basch J.J., Gordon W.J., Isolation, characterisation, and amino acid composition of a new erystaline protein, lactollin, from milk, Biochemistry 2 (1963) 814-819.

[35] Gueorguiev I.P., Bivolarski B.L., Kutsarov G.I., Iliev Y.I., Gueorguieva T.M., Serum lysozyme activity in new-born calves and relationship to milk yield of their mothers, Rev. Med. Vet. 147 (1996) 583-586.

[36] Guidry A.J., Butler J.E., Pearson R.E., Weinland B. T, IgA, IgG1, IgG2, IgM and BSA in serum and mammary secretion throughout lactation, Vet. Immunol. Immunopathol. 1 (1980) 329-341.

[37] Guidry A.J., Paape M.J., Pearson R.E., Effect of udder inflammation on milk immunoglobulins and phagocytosis, Amer. J. Vet. Res. 41 (1980) 751-753.

[38] Guimont C., Marchal E., Girardet J.M., Linden G., Biologically active factors in bovine milk and dairy by-products: influence on cell culture, Crit. Rev. Food Sci. Nutr. 37 (1997) 393-4I0.

[39] Guy M.A., McFadden T.B., Cockrell D.C., Besser T.E., Regulation of colostrum formation in beef and dairy cows, J. Dairy Sci. 77 (1994) 3002-3007.

[40] Haenlein G.F.W., Schultz L.H., Zikakis J.P., Composition of milk with varying leucocyte contents, J. Dairy Sci. 56 (1972) 1017-1024.

[41] Harmon R.J., Schanbacher F.L., Ferguson L.C., Smith K.L., Changes in lactoferrin, Immunoglobulin G, bovine serum albumin, and $\alpha$ lactalbumin during acute experimental and natural coliform mastitis in cows, Infec. Immunity 13 (1976) 533-542.

[42] Hidiroglou M., Mammary transfer of vitamine E in dairy cows, J. Dairy Sci. 72 (1989) 1067-1071.

[43] Hirado M., Tsunasawa S., Sakiyama F., Niinobe M., Fuji S., Complete amino acid sequence of bovine colostrum low-Mr cysteine proteinase inhibitor, Fed. Eur. Biochem. Soc. 186 (1985) $41-45$.

[44] Hirvonen J., Pyorala S,, Jousimies-Somer H., Acute phase response in heifers with experimentally induced mastitis, J. Dairy Res. 63 (1996) 351-360.

[45] Honkanen-Buzalsky T., Sandholm M., Trypsininhibitors in mastitic milk and colostrum: correlation between trypsin-inhibitor capacity. bovine serum albumin, and somatic cell contents, J. Dairy Res. 48 (1981) 213-223.

[46] Honegger A., Humbel R.E., Insulin-like growth factors $I$ and $I I$ in fetal and adult bovine serum. Purification, primary structure and immunological eross-reactivities, J. Biol. Chem. 261 (1986) 569-575.

[47] Hoschi F., Nagai D., Noso T., Takahashi A., Kawamura S., Purification of bovine $\beta 2$-microglobulin from colostrum and its complete amino acid sequence, Vet. Immunol. Immunopathol. 53 (1996) 29-38. 
[48] Humbert G., Collard-Bovy C., Marchal E., Linden G., Montagne P., Duheille J., Varcin P., Microparticle-enhanced nephelometric immunoassay. 3. Application to milk and dairy products, J. Dairy Sci. 74 (1991) 3709-3715.

[49] Humbert G., Guingamp M.F., Choukri A., Linden G., Method for the measurement of $\mathrm{N}$-acetyl- $\beta$-glucosaminidase activity in bovine milk, J. Dairy Res. 62 (1995) 369-372.

[50] Ibrahim E.M., Mohran M.A., El-Hoda Hanafy N., Physicochemical characteristics of colostrum and the influence of its addition on some technological properties of normal milk, Assiut J. Agric. Sci. 21 (1990) 221-239.

[51] Janusz M., Lisowski J.. Franek J., Isolation and characterization of a proline rich polypeptide from ovine colostrum, FEBS Lett. 49 (1974) 276-279.

[52] Janusz M., Straroscik K., Zimecki M., Wiezoreck Z., Lisowski J., Chemical and physical characterization of a proline-rich polypeptide from sheep colostrum, Biochem. J. 199 (1981) 9-15.

[53] Janusz M., Wiezoreck Z., Spiegel K., Kubik A., Szewczuk Z., Siemion I., Lisowski J., Immunoregulatory properties of synthetic peptides, fragments of a proline-rich polypeptide (PRP) from ovine colostrum, Mol. Immunol. 24 (1987) 1029-1031.

[54] Joisel F., Lannuzel B., Lebreton J.P, Boutleux S., Sauger F., Dosage immunonéplélométrique des immunoglobulines $\mathrm{G}$ dans le lait de vache. II. Application à la détection de la présence de colostrum dans les laits de mélange, Lait 61 (1981) 465-480.

[55] Julius M.H., Janusz M., Lisowski J.A., Colostral protein that induces the growth and differentiation of resting B lymphocytes, J. Immunol. 140 (1988) 1366-1371.

[56] Kaartinen L., Pyorala S., Changes in milk plasminogen, plasmin and in vitro bacterial growth in whey during early lactation, J. Dairy Res. 56 (1989) 719-725.

[57] Keller H.F., Chew B.P., Erb R.E., Malven P.V., Mammary transfer of hormones and constituents into secretions when cows were milked or secretions were sampled prepartum, J. Dairy Sci. 60 (1977) 546-557.

[58] Kiddy C.A., McCann R., Maxwell C., Rock C., Pierce C., Butler J.E., Changes in levels of immunoglobulins in serum and other body fluids immediately before and after parturition, J. Dairy Sci. 54 (1971) 1325-1327.

[59] Kincaid R.L., Cronrath J.D., Zinc concentration and distribution in mammary secretions of peripartum cows, J. Dairy Sci. 75 (1992) 481-484.

[60] Klagsbrun M., Bovine colostrum supports the serum-free proliferation of epithelial cells but not of fibroblasts in long term culture, J. Cell. Biol. 84 (1980) 808-814.
[61] Klagsbrun M., Neuman J., The serum-free growth of Balb/c 3T3 cells in medium supplemented with bovine colostrum, J. Supramol. Struct. 11 (1979) 349-359.

[62] Koning P.J., Jong J., Kaper J., Colostrum in cow milk. Pilot scale study on the situation in the Netherlands, Voedingsmiddelentechnologie 22 (1989) 24-26.

[63] Korhonen H., Antimicrobial factors in bovine colostrum, J. Sci. Agric. Soc. Finl. 49 (1977) 110-117.

[64] Kume I., Tanabe S, Effect of parity on colostral mineral concentrations of Holstein cows and value of colostrum as a mineral source for newborn calves, J. Dairy Sci. 76 (1993) 1654-1660.

[65] Kummer A., Kitts D.D., Li-Chan E., Losso J., Skura B., Nakai S., Quantification of bovine IgG in milk using enzyme-linked immunosorbent assay, Food Agric. Immunol. 4 (1992) 93-102.

[66] Larsen L.B., Benfeldt C., Rasmussen L.K., Petersen T.E., Bovine milk procathepsin D and cathepsine D: coagulation and milk protein degradation, J. Dairy Res. 63 (1996) 119-130.

[67] Larson B.L., Heary H.L., Devery J.E., Immunoglobulin production and transport by the mammary gland, J. Dairy Sci. 63, (1980) 665-671.

[68] Laskowski M. J., Laskowski M., Crystalline trypsin inhibitor from colostrum, J. Biol. Chem. 190 (1951) 563-573.

[69] Lecce J.G., Legates J.E., Changes in paper electrophoretic whey protein pattern of cows with acute mastitis, J. Dairy Sci. 42 (1959) 698-702.

[70] Lebreton J.P., Joisel F., Boutleux S., Lannuzel B., Sauger F., Dosage immunonéphélométrique des immunoglobulines $\mathrm{G}$ dans le lait de vache, Lait 61 (1981) 465-480.

[71] Levieux D., Évolution des immunoglobulines Gl du lait de vache au cours des quatre premiers mois de lactation : mesure dans neuf étables du Puy de Dôme, Bull. Techn. Cent. Zootech. Vet. Theix 33 (1978) 47-52.

[72] Levieux D., Transmission de l'immunité passive colostrale : le point des connaissances, in : Physiologie et pathologie périnatales chez les animaux de ferme, Inra Versailles, 1984 pp. 345-369.

[73] Levieux D., Immunoglobulines et transmission de l'immunité passive chez les ruminants, in : Pastoret P.P., Govaerts A. Bazin H. (éd.), Immunologie animale, Flammarion, Paris, 1990, pp. 596-599.

[74] Levieux D., Dosage des IgG du lait de vache par immunodiffusion radiale semi-automatisée, pour la détection du colostrum, des laits de mammites ou de fin de gestation, 1 . Mise au point du dosage, Lait 71 (1991) 327-338.

[75] Levieux D., Ollier A., Bovine immunoglobulin $\mathrm{G}, \beta$-lactoglobulin, $\alpha$-lactalbumin and serum albumin in colostrum and milk during the early post partum period, J. Dairy Res. 66 (1999), in press. 
[76] Levieux D., Retière Y., Determination of IgG1 level in herd milks as indicator of the presence of colostrum or late lactation milk, J. Dairy Res, 1999, accepted.

[77] Li-Chan E., Kummer A., Influence of standards and antibodies in immunochemical assays for quantitation of immunoglobulin $\mathrm{G}$ in bovine milk, J. Dairy Sci. 80 (1997) 1038-1046.

[78] Li-Chan E., Kummer A., Losso J.N,, Nakai S., Survey of immunoglobulin G content and antibody specificity in cows'milk from British Columbia, Food Agric. Immunol. 6 (1994) 443-451.

[79] Liebe A., Schams D., Growth factors in milk: interrelationships with somatic cell count, J. Dairy Res. 65 (1998) 93-100.

[80] Linden G., Maraval B., Colostrum de vache : composition minérale et activité de la phosphatase alcaline, Ann. Biol. Anim. Biochim. Biophys. 9 (1979) 337-341.

[81] Lowenstein H., Bjemum O.J., Weeke E., Weeke B., Characterization of bovine whey proteins by crossed immunoelectrophoresis, Scand. J. Immunol. 4 (1975) 155-161.

[82] Maes P., Damart D., Rommens C., Montreuil J., Spik G., Tartar A., The complete aminoacid sequence of bovine milk angiogenin, FEBS Lett. 241 (1988) 41-45.

[83] Mahieu H., Facteurs de variation de la composition du lait, in : Laits et produits laitiers. 1. Les laits de la mamelle à la laiterie, Luquet F.M. (éd.), Technique et Documentation Lavoisier, Paris, 1985, p. 127.

[84] Mancini G., Carbonara A.O., Heremans J.M., Immunological quantitation of antigens by single radial immunodiffusion, Immunochemistry 2 (1965) 235-254.

[85] Mao F.C., Bremel R.D., Prediction of milk yields from serum $\beta$-lactoglobulin concentrations in pregnant heifers, J. Dairy Sci. 78 (1995) 291-295.

[86] Mao F.C., Bremel R.D., Dentine M.R., Serum concentrations of the milk proteins $\alpha$-Lactalbumin and $\beta$-Lactoglobulin in pregnancy and lactation: correlations with milk and fat yields in dairy cattle, J. Dairy Sci. 74 (1991) 2952-2958.

[87] Mattila T., Saari S., Vartiala H., Sandholm M., Milk antitrypsin as a marker of bovine mastitis, Correlation with bacteriology, J. Dairy Sci. 68 (1985) $114-122$.

[88] McFadden T.B., Akers R.M., Capuco A.V., Relationship of milk proteins in blood with somatic cell counts in milk of dairy cows, J. Dairy Sci. 71 (1988) 826-834.

[89] McGuire T.C., Regnier J., Kellom T., Gates N.L., Failure in passive transfer of immunoglobulin G1 in calves, Amer. J. Vet. Res. 44 (1983) 1064-1067.

[90] Mechor G.D., Grohn Y.T., McDowell L.R., Van Saun R.J., Specific gravity of bovine colostrum immunoglobulins as affected by temperature and colostrum components, J. Dairy Sci. 75 (1992) 3131-3135.

[91] Merendino N., Prosperi S., Franci O., Tuosto L.. Piccolella $\mathrm{E}_{\text {, }}$ Tomassi G., Immunomodulatory activity of bovine colostrum on human peripheral blood mononuclear cells, J, Nutr. Immunol. 4 (1996) 5-21.

[92] Mesa M., Perez M.D. Calvo M., Presence and concentration of $\alpha_{1}$-acid glycoprotein in cow colostrum and milk and in mastitic cow milk, Milchwissenschaft 49 (1994) 607-610.

[93] Mitranic M.P., Paquet M.R., Moscarello M.A., The interaction of bovine milk galactosyltransferase with lipid and $\alpha$-lactalbumin, Biochim. Biophys. Acta 956 (1988) 277-284.

[94] Muller L.D., Ellinger D.K., Colostral immunoglobulin concentrations among breeds of dairy cattle, J. Dairy Sci. 64 (1981) 1727-1730.

[95] Newstead D.F., Caroten and immunoglobulin concentrations in the colostrum and milk of pasture-fed cows, J. Dairy Res. 43 (1976) 229-237.

[96] Ng-Kwai-Hang K.F., Hayes J.F., Moxley J.E., Monardes H.G., Variation in milk protein concentrations associated with genetic polymorphism and environmental factors, J. Dairy Sci. 70 (1987) 563-570.

[97] Norcross N.L., Secretion and composition of colostrum and milk, J. Amer. Vet. Med. Assoc. 181 (1982) 1057-1060.

[98] Ost M., Guidry A.J., Shainline W.E., Sequential response of milk leukocytes, serum-albumin, immunoglobulins and electrical conductivity following infusion of $E$. coli endotoxin into the bovine mammary gland, J. Dairy Sci. 61 (Suppl. 1) (1978) 159-160.

[99] Ostersen S., Foldager J., Hermansen J.E., Effects of stage of lactation, milk protein genotype and body condition at calving on protein composition and renneting properties of bovine milk, J. Dairy Res. 64 (1997) 207-219.

[100] Pakkanen R., Bovine colostrum ultrafiltrate supplemented with adult bovine serum and transferrin: an effective FBS substitute for cultivation of vero and $\mathrm{CHO} \mathrm{Kl}$ cells, in vitro Cell. Develop. Biol. 30A (1994) 295-299.

[101] Pakkanen R., Neutra M., Bovine colostrum ultrafiltrate: an effective supplement for the culture of mouse-mouse hybridoma cells, J. Immunol. Methods 169 (1994) 63-71.

[102] Pakkanen R., Kanttinen A., Satama L., Aalto J., Bovine colostrum fraction as a serum substitute for the cultivation of mouse hybridomas, Appl. Microbiol. Biotechnol. 37 (1992) 451-456.

[103] Perez M.D., Sanchez L., Aranda P., Sala F.J., Calvo M., Time-course levels of $\alpha_{2}$-macroglobulin and albumin in cow colostrum and milk and $\alpha_{2}$-macroglobulin levels in mastitic cow milk, Ann. Rech. Vet. 20 (1989) 251-258. 
[104] Perez M.D., Sanchez L., Aranda P., Ena J.M. Oria R., Calvo M., Synthesis and evolution of concentration of $\beta$-lactoglobulin and $\alpha$-lactalbumin from cow and sheep colostrum and milk throughout early lactation, Cell. Mol. Biol. 36 (1990) 205-212.

[105] Pineiro A,, Brock J.H., Esparza I., Isolation and purification of bovine colostral trypsin inhibitor, Ann. Rech. Vet. 9 (1978) 281-286.

[106] Poutrel B., Caffin J.P., Rainard P., Physiologi$\mathrm{cal}$ and pathological factors influencing bovine serum albumin content of milk, J. Dairy Sci. 66 (1983) 535-541.

[107] Precetti A.S., Oria M.P., Nielsen S.S., Presence in bovine milk of two protease inhibitors of the plasmin system, J. Dairy Sci. 80 (1997) 1490-1496.

[108] Pritchett L.C., Gay C.C., Besser T.E., Hancock D.D., Management and production factors influencing immunoglobulin $\mathrm{G}_{1}$ concentration in colostrum from Holstein cows, J. Dairy Sci. 74 (1991) 2336-2341.

[109] Quesnel F., L'utilisation de colostrum par les producteurs de lait, EDE Seine-Maritime, France, 1981.

[110] Quigley J.D., Martin K.R., Dowlen L.B., Wallis L.B., Kamar J.. Immunoglobulin concentration, specific gravity, and nitrogen fractions of colostrum from Jersey cattle. J. Dairy Sci. 77 (1994) 264-269.

[111] Quigley J.D., Martin K.R., Dowlen H.H., Concentration of trypsin inhibitor and immunoglobulins in colostrum of jersey cows, J. Dairy Sci. 78 (1995) 1573-1577.

[112] Rainard P., Caffin J.P., Sequential changes in serum albumin, immunoglobulin $\left(\mathrm{IgG}_{1}, \mathrm{IgG}_{7}\right.$, $\mathrm{IgM}$ ) and lactoferrin concentrations in milk following infusion of Escherichia coli into the udder of immunised and unimmunised cows, Ann. Rech. Vet. 14 (1983) 271-279.

[113] Rainard P., Poutrel B., Caffin J.P., Lactoferrin and transferrin in bovine milk in relation to certain physiological and pathological factors, Ann. Rech. Vet. 13 (1982) 321-328.

[114] Ramirez O.T., Suershkumar G.K., Mutharasan R., Bovine colostrum or milk as a serum substitute for the cultivation of a mouse hybridoma, Biotechnol. Bioeng. 35 (1990) 882-889.

[115] Randolph H.E., Erwin R.E., Richter R.L., Influence of mastitis on properties of milk. VII. Distribution of milk proteins, J. Dairy Sci. 57 (1974) $15-23$.

[116] Regester G.O., Smithers G.W., Seasonal changes in the $\beta$-lactoglobulin, $\alpha$-lactalbumin, glycomacropeptide, and casein content of whey protein concentrate, J. Dairy Sci. 74 (1991) 796-802.

[117] Reiter B., Review of nonspecific antimicrobial factors in colostrum, Ann. Rech. Vet. 9 (1978) 205-224.

[118] Reiter B., The biological significance and exploitation of the non-immunoglobulins pro- tective proteins in milk: Lysozyme, lactoferrin, lactoperoxydase, xanthinoxidase, bulletin $n^{\circ} 191$, Int. Dairy Fed. Brussels, Belgium, 1985.

[119] Rémond B., Bonnefoy J.C., Performance of a herd of Holstein cows managed without the dry period, Ann. Zootech. 46 (1997) 3-12.

[120] Rémond B., Ollier A., Miranda G., Milking of cows in late pregnancy: milk production during this period and during the succeeding lactation, J. Dairy Res. 59 (1992) 233-241.

[121] Rémond $B_{i}$, Macheboeuf $D_{*}$, Rouel $J_{*}$, Chilliard $Y_{*}$, Composition chimique et coagulation du lait sécrété en fin de gestation et au début de la lactation suivante par des vaches laitières conduites sans période sèche, Lait 77 (1997) 615-624.

[122] Rémond B., Rouel J., Pinson N., Jabet S., An attempt to omit the dry period over three consecutive lactations in dairy cows, Ann. Zootech. 46 (1997) 399-408.

[123] Rochaix A., Tapernoux A., Les laits anormaux, in : Vigot frères (éd.), Le lait et ses dérivés, Paris, 1942, p. 115.

[124] Salih A.M., Anderson M., Effect of diet and stage of lactation on bovine milk lipolysis, J. Dairy Res. 46 (1979) 623-631.

[125] Sambasaravao D., Dost A., Paetkau V., A novel immunosuppressive factor in bovine colostrum blocks activation of the interleukine 2 gene enhancer at the NFAT site, Biochem. Cell. Biol. 74 (1996) 585-593.

[126] Sanchez L., Aranda P., Perez M.D., Calvo M., Concentration of lactoferrin and transferrin throughout lactation in cow's colostrum and milk, Biol. Chem. Hoope-Seyler 369 (1988) 1005-1008.

[127] Sandholm M.R., Honkanen-Buzalsky T., Colostral trypsin inhibitor capacity in different species, Acta Vet. Scand. 20 (1979) 469-475.

[128] Shutt D.A., Fell L.R., Comparison of total and free cortisol in bovine serum and milk or colostrum, J. Dairy Sci. 68 (1985) 1832-1834.

[129] Senft B., Klobasa F., Untersuchungen über die konzentration an lactoferrin in kolostralmilch und reifer milch von kühen, Milchwissenschaft 28 (1973) 750-752.

[130] Shafer-Weaver K.A., Sordillo L.M., Enhancing bactericidal activity of bovine lymphoid cells during the periparturient period, J. Dairy Sci. 79 (1996) 1347-1352.

[131] Shing Y.W., Klagsbrun M., Human and bovine milk contain different sets of growth factors, Endocrinology 115 (1984) 273-282.

[132] Shuster D.E., Harmon R.J., Enzyme immunoassay of bovine lactoferrin and serum albumin in acid precipitated and ultracentrifuged wheys, J. Dairy Sci. 73 (1990) 3104-3111.

[133] Smith A., Wheelock J.V., Dodd F.H., The effect of milking throughout pregnancy on milk secretion in the succeeding lactation, J. Dairy Res. 34 (1967) 145-150. 
[134] Sordillo L.M., Shaffer-Weaver K., Derosa D., Immunobiology of the mammary gland, J. Dairy Sci. 80 (1997) 1851-1865.

[135] Sorensen J.T., Enevoldsen C., Effect of dry period length on milk production in subsequent lactation, J. Dairy Sci. 74 (1991) 1277-1283.

[136] Steimer K.S., Klagsbrun M., Serum-free growth of normal and transformed fibroblasts in milk: differential requirements for fibronectin. J. Cell. Biol. 88 (1981) 294-300.

[137] Steimer K.S., Packard R., Holden D., Klagsbrun $M$., The serum-free growth of cultured cells in bovine colostrum and milk obtained later in the lactation period, J. Cell. Physiol. 109 (1981) 223-234.

[138] Stevenson E.M., Law J.R., Leaver J., Heatinduced aggregation of whey proteins is enhanced by addition of thiolated $\beta$-casein, J. Agric. Food Chem. 44 (1996) 2825-2828.

[139] Stoeck M., Ruegg C., Miescher S,, Carrel S., Cox D., Fliedner V., Alkan S., Comparison of the immunosuppressive properties of milk growth factor and transforming growth factors $\beta 1$ and $\beta 2$, J. Immunol. 143 (1989) 3258-3265.

[140] Suchanek B., Sebela F., Picmanova B., Effets du colostrum sur les propriétés technologiques du lait, in : $20^{\mathrm{e}}$ Congrès International de Laiterie, Paris, Synaps Neuilly France, 1978. pp. 759-760.

[141] Svanson T.L., Moore G.E., Bovine mammary gland contains a growth promoter for human breast cancer cell lines: colo 278 and colo 384. Biochem. Biophys. Res, Commun, 4 (1979) 1166-1171

[142] Targowski S.P., Niemaltowski M., Cytotoxic and blocking effect of bovine colostrum, J. Vet. Med. 35 (1988) 96-104.

[143] Thompson J.C., Pauli J.P., Colostral transfer of gamma glutamyl transpeptidase in calves, N. Z . Vet. J. 29 (1981) 223-226.

[144] Tsuji S., Hirata Y., Mukai F., Ohtagaki S., Comparaison of lactoferrin content in colostrum between cattle breeds, J. Dairy Res. 73 (1990) $125-128$.

[145] Vacher P.Y., Blum J.W., Age-dependency of insulin-like growth factor $\mathrm{I}$, insulin, protein and immunoglobulin concentrations and $\gamma$-glutamyltransferase activity in first colostrum of dairy cows, Milchwissenschaft 48 (1993) 423-426.

[146] Viljoen M.H., The isolation and identification of an antigen for the diagnosis of bovine mastitis by radial immunodiffusion test, Onderstepoort J. Vet. Res. 41 (1974) 93-96.

[147] Wahab I., Anderson R.R., Ireland F., Loch W., Periparturient changes in immunoreactive insulin (IRI) concentrations of bovine, equine and ovine colostrum, milk and blood serum, J. Dairy Sci. 72 (1989) 313-323

[148] Watanabe A., Miyamoto T., Katoh N., Takahashi Y., Effect of stages of lactation on the concentration of a 90-kilodalton heat shock protein in bovine mammary tissue, J. Dairy Sci. 80 (1997) 2372-2379.

[149] Watson D.L., Francis G.L., Ballard F,J., Factors in ruminant colostrum that influence cell growth and murine IgE antibody response, J. Dairy Res. 59 (1992) 369-380.

[150] Weber B.A., Nielsen S.S.. Isolation and partial characterization of a native serine-type protease inhibitor from bovine milk, J. Dairy Sei. 74 (1991) 764-771.

[151] Welty F.K., Larry Smith K., Schanbacher F.L., Lactoferrin concentration during involution of the bovine mammary gland, J. Dairy Sci. 59 (1976) 224-231.

[152] Wheelock J.V., Rook J.A.F., Dodd F.H., The effect of milking throughout the whole pregnancy on the composition of cow's milk, J. Dairy Res. 32 (1965) 249-254.

[153] Wiezoreck Z., Zimecki M.. Janusz M., Staroscik K., Lisowski J., Proline-rich polypeptide from ovine colostrum: its effect on skin permeability and on the immune response, Immunology 36 (1979) $875-881$.

[154] Williams D.J., Marschke R., Nottingham S.M., Kitchen B.J., Effect of stage of lactation, number of lactations and dry period on $\mathrm{N}$-acetyl$\beta$-D-glucosaminidase levels and somatic cell count in bovine milk, Aust. J. Dairy Technol. 46 (1991) 43-45.

[155] Wilson W.E., Lazarus L.H., Tomer K.B., Bradykinin and kininogens in bovine milk, J. Biol. Chem. 264 (1989) 17777-17783.

[156] Zawistowski J., MacKinnon R., Incidence of colostrum in raw milk, J. Food Protect. 56 (1993) 625-626.

[157] Zehetner G., Bareuther C., Henle T., Klostermeyer H., Endogenous milk enzymes as indicators for low heat treatment of milk, in: Heat treatments and alternative methods, Proceedings Vienne Autriche 6-8 septembre 1995. Int. Dairy Fed,, Brussels, Belgique, 1996. pp. 403-408.

[158] Zimecki M., Lisowki J., Hiraba T., Wiezoreck Z., Janusz M., Staroscik K., The effect of a prolinerich polypetide (PRP) on the humoral immune response I. Distinct effect of PRP on the T-cell properties of mouse glass-nonadherent (NAT) and glass-adherent (GAT) thymocytes in thymectomized mice, Arch. Immunol. Therap. Exp. 32 (1984) 191-196.

[159] Zimecki M., Lisowki J., Hiraba T., Wiezoreck Z. Janusz M., Staroscik K., The effect of a prolinerich polypetide (PRP) on the humoral immune response II. PRP induces differenciation of helper cells from glass-nonadherent thymocytes (NAT) and suppressor cells from glass-adherent thymocytes (GAT), Arch. Immunol. Therap. Exp. 32 (1984) 197-201. 